\title{
An Experimental and Simulation Study of Early Flame Development in a Homogeneous-Charge Spark-Ignition Engine
}

\author{
Y. Shekhawat ${ }^{1}$, D.C. Haworth ${ }^{1,}$, A. d'Adamo ${ }^{2}$, F. Berni ${ }^{2}$, S. Fontanesi ${ }^{2}$, P. Schiffmann ${ }^{3}$, \\ D.L. Reuss ${ }^{3}$ and V. Sick ${ }^{3}$ \\ ${ }^{1}$ Department of Mechanical \& Nuclear Engineering, The Pennsylvania State University, University Park, PA - USA \\ 2 Department of Engineering "Enzo Ferrari", University of Modena and Reggio Emilia, Modena - Italy \\ ${ }^{3}$ Department of Mechanical Engineering, University of Michigan, Ann Arbor, MI - USA \\ e-mail: dch12@psu.edu \\ *Corresponding author
}

\begin{abstract}
An integrated experimental and Large-Eddy Simulation (LES) study is presented for homogeneous premixed combustion in a spark-ignition engine. The engine is a single-cylinder two-valve optical research engine with transparent liner and piston: the Transparent Combustion Chamber (TCC) engine. This is a relatively simple, open engine configuration that can be used for LES model development and validation by other research groups. Pressure-based combustion analysis, optical diagnostics and LES have been combined to generate new physical insight into the early stages of combustion. The emphasis has been on developing strategies for making quantitative comparisons between high-speed/high-resolution optical diagnostics and LES using common metrics for both the experiments and the simulations, and focusing on the important early flame development period. Results from two different LES turbulent combustion models are presented, using the same numerical methods and computational mesh. Both models yield Cycle-to-Cycle Variations (CCV) in combustion that are higher than what is observed in the experiments. The results reveal strengths and limitations of the experimental diagnostics and the LES models, and suggest directions for future diagnostic and simulation efforts. In particular, it has been observed that flame development between the times corresponding to the laminar-to-turbulent transition and 1\% mass-burned fraction are especially important in establishing the subsequent combustion event for each cycle. This suggests a range of temporal and spatial scales over which future experimental and simulation efforts should focus.
\end{abstract}

\section{INTRODUCTION}

Cycle-to-Cycle Variations (CCV) of flow and combustion in spark-ignition engines have been the subject of extensive research over the last few decades [1]. High-speed/highresolution optical diagnostics and Large-Eddy Simulation (LES) have been brought to bear to understand the root causes of $\mathrm{CCV}$, and significant progress has been made in that regard. Multiple sources of variability have been identified. These include local variations in the flow, temperature and mixture composition, and in the spark discharge, as well as global variations in equivalence ratio, dilution and trapped mass [2-5]. While these contributing factors have been recognized for some time, their interactions and influences on combustion remained unclear due to a lack of multi-diagnostic data and the difficulty of performing accurate LES simulations over a sufficiently large number of cycles. Lacour and Pera [5] and Baum et al. 
[6] performed multi-diagnostic experiments that allow a deeper understanding of the coupled physics in engines. And recently these interactions have been investigated using multi-parameter experimental $[6,7]$ and simulation $[6,8]$ approaches.

Earlier experimental and simulation studies (e.g., $[9,10])$ have shown that what happens during the earliest stages of combustion can determine, to a large extent, the subsequent combustion process for that cycle. Under realistic engine operating conditions, the velocity magnitude $[7,8]$ and velocity gradient parameters [7] in the vicinity of the spark plug at the time of ignition have been found to correlate with the Indicated Mean Effective Pressure (IMEP) for the cycle. Motivated by the difficulties of making accurate pressurebased combustion measurements during the early flame development period, some LES studies have focused on early-flame-kernel development, toward developing an understanding of the governing factors that result in cyclic variation of flame growth. Granet et al. [11] demonstrated that initial flame convection within the spark plug gap is a probable reason for incomplete combustion cycles due to local quenching, while Goryntsev et al. $[12,13]$ emphasized the superposition of flow variation and mixture quality for direct-injection engines, whose combined effect on combustion CCV was elucidated by LES.

For these reasons, the focus here is on the early burn: ignition through fully developed turbulent flame. A specific goal is to assess the predictive capability of two different ignition and turbulent flame propagation models, using the same CFD code and computational mesh. The approach is to compare the simulated and measured combustion using a single set of metrics that are applicable to both the simulated and measured data, focusing on the early burn. The metrics are derived from in-cylinder pressure and high-speed optical measurements, and are applied to perform equivalent analysis of the simulation data. The study was conducted in a research engine that exhibits high cycle-to-cycle variability. As will be shown later, fast and slow burning cycles are established during the Early Flame Development (EFD), defined here as the period between the Start of Ignition (SOIgn) and a fully developed turbulent flame. Variation of the EFD duration (either between the experiments and simulations, or between individual cycles in either the experiments or the simulations) changes the combustion phasing, and thus is effectively the same as variability in the ignition timing. Thus, the turbulent flame propagation after the EFD encounters earlier or later thermodynamic states and turbulence properties from one cycle to another. In turn, the resulting combustion-phase variability affects the production of work (IMEP) and the time for completion of combustion (combustion efficiency), as revealed by experimental pressure-based combustion analysis $[14,15]$. Thus, improper simulation of EFD will result in improper pressure or mass burned fraction evolution, even if the turbulent flame propagation model is perfect. This motivates the focus on EFD for this study.

Historically, the EFD period has been characterized using the Mass-Burned Fraction (MBF) of the combustion progress, computed from an Apparent Heat Release (AHR) analysis based on the measured in-cylinder pressure trace. Typically, a crank angle corresponding to between one and ten percent MBF (CA01-CA10) is the earliest value that is sufficiently resolved experimentally, and that has been used as the metric to characterize the EFD variability. Although values as low as CA01 can be calculated from the pressure data, single-cycle analysis has high uncertainty due to recording noise and the large dynamic range requirements for the pressure transducer and recording system (here 40$2000 \mathrm{kPa}$ ). As a second EFD metric, the transition between slow and rapid flame growth has been measured optically. Beretta et al. [16] observed the early-flame-growth period between the start of ignition and the transition to a turbulent flame, which they defined in terms of the transition from a laminar to a turbulent characteristic time scale. This concept was introduced for modeling ignition in RANS simulations by Abraham et al. [17]. The duration of this laminar-toturbulent transition period, $\tau_{\text {lam-turb }}$, is measured here from the two-dimensional area projection of the three-dimensional flame volume, as computed from both the optical flame measurements and the LES. The laminar-to-turbulent transition is quantified as the time-scale transition revealed in the $\log \left(A_{\text {Flame }}\right)$ versus $\log (t)$ plots (where $A_{\text {Flame }}$ is the time-varying flame area), as suggested by Arpaci et al. [18]. It is demonstrated that $\tau_{\text {lam-turb }}$ occurs at a MBF much less than one percent in the experiments.

An emphasis in this paper is to apply equivalent metrics to compare results from the experimental measurements with results from two different LES ignition and turbulent combustion models, focusing on the EFD period. As will be shown later, both models were found to produce higher variability than the experiment. Both the measured and simulated cycles show that the combustion phasing of earlyand late-burning cycles is established by CA10. The projected flame-area growth rate between the start of the spark discharge (SOIgn) and CA10 is compared to $\tau_{\text {lam-turb, }}$ to CA01, and to the spark-plasma duration to estimate the time and length scales of the flame kernel during these periods. To assess the causes of the reasons for the disparity between the experiments and simulations, both the thermodynamic and the flow properties at SOIgn are compared.

Contributions of this paper are: (1) the first comparisons between combustion LES and experiment for a configuration that is fully accessible to other research groups; (2) comparisons of results from two different LES turbulent combustion models using the same mesh and numerics; and 


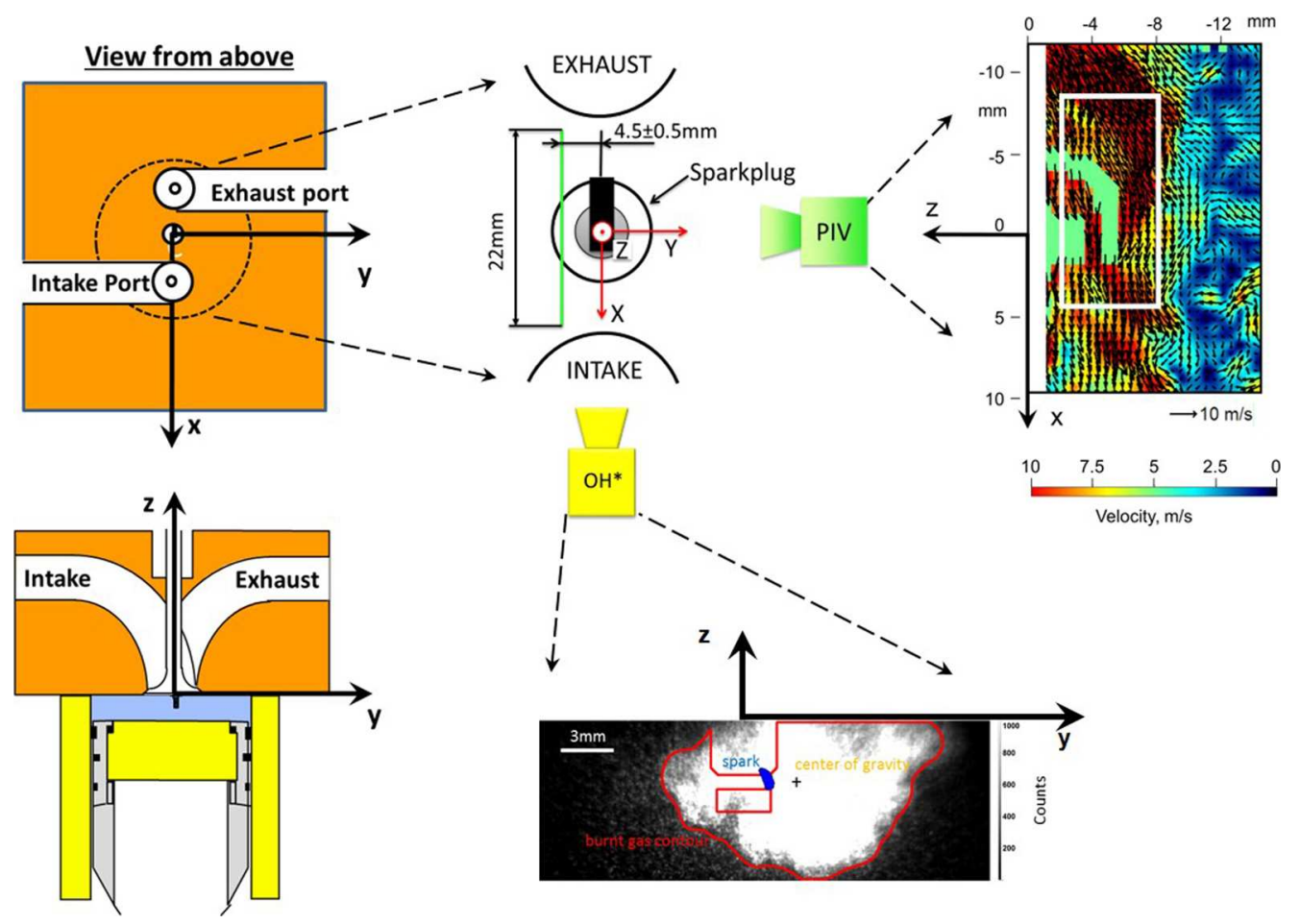

Figure 1

Schematic illustration of the TCC-III engine showing the coordinate system, PIV measurement plane $(y=-4.5 \mathrm{~mm})$ and the flame imaging fields-of-view. The white box in the PIV field-of-view image shows a $12 \times 6 \mathrm{~mm}$ region near the spark plug $(x=4$ to $-8 \mathrm{~mm}, z=-2$ to $-8 \mathrm{~mm})$ in which flow parameters have been averaged in the subsequent analysis.

(3) combining pressure-based combustion analysis, optical diagnostics and LES to generate new physical insight into the early stages of combustion and the limitations of current modeling approaches. Specific questions that are addressed include:

- Are there specific local or global conditions that result in a fast cycle versus a slow cycle?

- Can useful criteria/metrics be established for the transition between ignition and fully developed turbulent flame propagation?

- What controls the heat release rate during the early burn?

- How well do current LES models represent this phase of combustion?

- What experiments/models are needed to make further progress in understanding and modeling the early burn?

\section{ENGINE EXPERIMENTS}

The University of Michigan transparent combustion chamber (TCC-III) optical engine is illustrated in Figure 1 [19-21]. This is a single-cylinder, spark-ignited, two-valve, four-stroke-cycle, pancake-shaped-combustion-chamber engine with a transparent liner and piston. The geometric compression ratio is $10: 1$, and bore $\times$ stroke are $92 \times 86 \mathrm{~mm}$. This is a research engine that has been developed specifically to facilitate optical access for Particle-Image Velocimetry (PIV) and other high-fidelity laser-based diagnostics, as well as simple mesh generation for CFD. This geometrically simple engine configuration is known to exhibit highly variable in-cylinder flow. The combination of a pancake-shaped combustion chamber, large piston-to-valve diameter ratio $(92 \mathrm{~mm} / 30 \mathrm{~mm})$, and undirected ports produces large CCV of the large-scale, motored flow structures $[22,23]$. Details of the geometric configuration and operating conditions, and extensive motored engine PIV data, are available at [21]. Several groups have been using the motored TCC engine data to test and validate physical models and numerical algorithms for in-cylinder LES [19, 20, 23-25].

The measured combustion data are from the fired TCC-III engine experiments conducted by Schiffmann [7]. There, the measured data for a range of operating conditions (lean, rich, $\mathrm{N}_{2}$ dilution, methane fuel, propane fuel) were analyzed to explore the sources of CCV. This first comparison between simulated and measured combustion data is conducted at a robust combustion condition: $40 \mathrm{kPa}$ Manifold Absolute Pressure (MAP), $1300 \mathrm{rpm}$, stoichiometric premixed propane-air reactants, and no $\mathrm{N}_{2}$ dilution. Ignition was at 342 crank angle degrees after Top-Dead-Center exhaust ( ${ }^{\circ}$ TDCe). The $40 \mathrm{kPa} / 101.5 \mathrm{kPa}$ intake/exhaust manifold absolute pressures result in back-flow during exhaust-valve 
TABLE 1

TCC-III engine geometry, valve timing and operating condition.

\begin{tabular}{|c|c|c|c|}
\hline Bore $(\mathrm{cm})$ & 9.20 & Exhaust-Calve Closing (EVC) ( ${ }^{\circ}$ aTDCe) & 12.8 \\
\hline Stroke $(\mathrm{cm})$ & 8.60 & Intake-Valve Closing (IVC) $\left({ }^{\circ}\right.$ aTDCe) & 240.8 \\
\hline Clearance@TDC (cm) & 0.95 & Exhaust-Valve Opening (EVO) $\left({ }^{\circ}\right.$ aTDCe) & 484.8 \\
\hline Combustion chamber volume (cc) & 63.15 & Intake-Valve Opening (IVO) $\left({ }^{\circ}\right.$ aTDCe) & 712.8 \\
\hline Top-land crevice volume (cc) & 0.37 & Steady-flow swirl ratio & 0.4 \\
\hline Spark-plug crevice volume (cc) & 0.02 & Engine speed (rpm) & 1300 \\
\hline Swept volume (cc) & 571.7 & Intake MAP $(\mathrm{kPa})$ & 40 \\
\hline Geometric Compression Ratio (CR) & 10.0 & Exhaust MAP (kPa) & 101.5 \\
\hline Effective (IVC) CR & 8.0 & Fuel & Propane \\
\hline Connect.-rod length $(\mathrm{cm})$ & 23.1 & Equivalence ratio & 1.0 \\
\hline Piston-pin offset (cm) & 0.0 & SOIgn ( ${ }^{\circ}$ aTDCe $)$ & 342 \\
\hline
\end{tabular}

opening and valve overlap periods. Details of the engine and optical methods can be found in [7]. Engine and operating parameters key to this paper are provided in Table 1, and details are available at [21].

In-cylinder pressure measurements were recorded every 0.5 Crank-Angle Degrees (CAD) of rotation. The AHR analysis was performed on both the measured and simulated pressure traces using the same crank-angle resolution and similar values of the polytropic coefficients $n$; for the experiments, individual-cycle values of $n$ were used [7], whereas averaged values were used for the LES. The instantaneous heat release for crank-angle interval $i$ is given by

$$
\begin{gathered}
q_{i}=\frac{n^{*} p_{i} *\left(v_{i}-v_{i-1}\right)+v_{i}^{*}\left(p_{i}-p_{i-1}\right)}{n-1}, \\
n_{i}=-\frac{\ln p_{i}-\ln p_{i-1}}{\ln v_{i}-\ln v_{i-1}}, \\
n=\left\{\begin{array}{c}
n_{\text {compression for } \mathrm{CA}<360^{\circ} \mathrm{aTDCe},} \\
\text { ave. } 260-325^{\circ} \mathrm{aTDCe} \\
n_{\text {expansion for } \mathrm{CA}<360^{\circ} \mathrm{aTDCe},} \\
\text { ave. } 440-480^{\circ} \mathrm{aTDCe}
\end{array}\right.
\end{gathered}
$$

The cumulative heat release $(Q)$ is then computed by integrating equation (1), and the AHR-based mass-burned fraction is given by $\mathrm{MBF}=Q / Q_{\text {total }}$, where $Q_{\text {total }}=Q_{\max }$.

Imaging of $\mathrm{OH}^{*}$ chemiluminescence (Fig. 1) was used to measure the area of the two-dimensional projection of early flame growth with $0.5 \times 0.5 \mathrm{~mm}$ spatial resolution. High-speed imaging was used to acquire images every 2 CAD from SOIgn ( $\left.342^{\circ} \mathrm{aTDCe}\right)$ to top-dead-center combustion (corresponding to an average MBF of approximately CA10), at which time the flames had grown outside of the field of view. The $\mathrm{OH}^{*}$ signal was filtered by a combination of optical filters (UG11 and a $330 \mathrm{~nm}$ short-pass filter) that is centered on $307 \mathrm{~nm}$ with a $25 \mathrm{~nm}$ wide $10 \%$ cut-off to isolate the $306.4 \mathrm{~nm}$ band from emissions of other major combustion products over $330 \mathrm{~nm}$ [26]. To account for spatial differences in intensifier efficiencies, all acquired images were first white-field corrected and a spatial calibration was applied. Then a binarization threshold was determined by the average value of the maximum values in each pixel column. The parameterization of this threshold improves capturing the burned-gas-area region and allows a higher degree of automation. The flame-kernel growth rate can be quantified in this manner prior to the time when acceptable pressure measurements are available, and the measured growth rates then can be compared with the simulated flamekernel growth rates.

High-speed PIV was used to measure the twodimensional, two-component velocity in the plane $y=$ $-4.5 \mathrm{~mm}$ near the spark plug (Fig. 1). The present analysis focused on data from a $6 \times 12 \mathrm{~mm}$ region $(x: z=-2 \rightarrow-8$ $\mathrm{mm}:-8 \rightarrow+4 \mathrm{~mm}$ ), as shown with the white box in Figure 1. The spatial resolution was $1 \mathrm{~mm}$, and was determined by the $1 \mathrm{~mm}$ thick laser sheet and the $1 \times 1 \mathrm{~mm}$ $(32 \times 32$ pixel) interrogation spots on a $0.5 \times 0.5 \mathrm{~mm}$ grid (50\% interrogation-spot overlap). The velocity dynamic range was $0.6-25 \mathrm{~m} / \mathrm{s}$, as determined by the 0.2 -to-8-pixel PIV resolution. The velocity gradients were computed using central differencing on the grid interior, with onesided differencing at the boundaries. The measurement plane was offset by $4.5 \mathrm{~mm}$ from the spark gap $(y=-4.5$ mm, Fig. 1) to avoid scattering from the spark-plug elements. Details of the PIV measurement procedures are provided in [7]. 


\section{NUMERICAL SIMULATIONS}

LES has been performed using STAR-CD v4 [27]. The computational domain includes the in-cylinder region, intake and exhaust ports, and intake and exhaust plenums. The average in-cylinder mesh size is approximately $0.75 \mathrm{~mm}$, with finer meshes near the spark-plug tip and in the valve-curtain regions. Time-dependent pressure and temperature boundary conditions from a one-dimensional model are prescribed at the plenum inlet/outlet, with no CCV [19]. A standard Smagorinsky subfilter-scale turbulence model is used. Results from two different ignition and turbulent flame propagation models (designated as Model 1 and Model 2) are presented, with all other numerical, flow and heat transfer modeling aspects being the same. For each combustion model, 60 engine cycles have been simulated. For Model 1, three blocks of 20 consecutive cycles were simulated, whereas for Model 2, four blocks of 15 consecutive cycles were simulated. The same initial conditions were used for both models, which were obtained from different cycles of a preliminary LES study where a different subfilter-scale turbulence model and turbulent combustion model were used. No patterns of correlation between different blocks of cycles were evident, as shown in Figure 2.

\subsection{Model 1}

Model 1 uses a simple energy deposition model for ignition, and a modified Thickened Flame Model (TFM) [28] implemented by the authors for turbulent flame propagation. The energy deposition model creates a spherical temperature source with a radius of $0.75 \mathrm{~mm}$, a temperature of $3000 \mathrm{~K}$, and a duration of 4.0 crank angle degree. This hightemperature source initiates a flame based on a two-step global propane-air chemical mechanism [11], which has been tuned to give the correct laminar flame speed and adiabatic flame temperature for the engine conditions of interest. After the flame initiation, the thickened flame model takes over to propagate the flame. The essential features of the thickened flame model can be understood in terms of classical thermal theory for laminar premixed flames, according to which the laminar flame speed $s_{l}^{0}$ is proportional to the square root of the product of the molecular diffusivity $D$ and the reaction rate $\omega$, and the laminar flame thickness $\delta_{l}^{0}$ is proportional to the square root of the quotient of $D$ and $\omega$ :

$$
s_{l}^{0} \propto \sqrt{D \omega}, \quad \delta_{l}^{0} \propto \sqrt{D / \omega} .
$$

The first essential idea in TFM is to multiply the diffusivity $D$ and to divide the chemical source term $\omega$ in the species and enthalpy equations by the same factor $F$. From equation (2), it follows that this increases the flame thickness $\delta_{l}^{0}$ by the factor $F$ (for $F>1$ ), while the laminar flame speed $s_{l}^{0}$ (or equivalently, the mass rate of reactant consumption) remains unchanged. This suggests an approach by which one can recover the correct burn rate in an "under-resolved" numerical simulation of a flame where the underlying flame structure is not fully resolved: choose $F$ to be the ratio of the actual mesh size to the mesh size that is needed to fully resolve the underlying flame structure (typically $\sim 0.1 \delta_{l}^{0}$ ). In LES of turbulent flames, an additional factor is needed to account for the wrinkling of the flame (thereby enhancing the local burn rate) by unresolved turbulence scales. The second essential element in TFM, then, is to maintain the correct overall burn rate (or turbulent flame speed) in a numerical simulation of a turbulent flame, even when all turbulence scales are not fully resolved. This effect is implemented through a multiplicative factor $\Xi$ that is applied to both the diffusive term and the chemical source term in the species and enthalpy equations. Multiplying both $D$ and $\omega$ in equation (2) by the same factor $\Xi$ increases the flame speed (or mass rate of reactant consumption) by the factor $\Xi$ (for $\Xi>1$ ), without changing the flame thickness. In contrast to $F, \Xi$ has a rather complicated functional form that depends on local turbulence parameters, and that is informed by theoretical analysis and by direct numerical simulations. The resulting species mass fraction $\left(Y_{m}\right)$ equation is then:

$$
\frac{\partial \rho Y_{m}}{\partial t}+\frac{\partial \rho u_{i} Y_{m}}{\partial x_{i}}=\frac{\partial}{\partial x_{i}}\left(\rho \Xi F D_{m} \frac{\partial Y_{m}}{\partial x_{i}}\right)+\Xi \frac{\omega_{m}}{F},
$$

and similarly for enthalpy. The factors $F$ and $\Xi$ are applied only within the turbulent flame brush. Several models for $\Xi$ have been formulated. Charlette et al. [29] proposed the following power-law:

$$
\Xi=\left(1+\min \left[\frac{\Delta}{\delta_{l}^{0}}, \Gamma \frac{u_{\Delta}^{\prime}}{s_{l}^{0}}\right]\right)^{\beta}
$$

Here $\Delta=F \delta_{l}^{0}$ is the combustion filter size, $\beta$ is a model constant, the function $\Gamma$ represents the integration of turbulent strain rate induced by scales smaller than $\Delta$ (which is fitted by a function [29]), and $u_{\Delta}^{\prime}$ is the subfilter-scale velocity fluctuation. An expression for the latter was proposed by Colin and Truffin [30]:

$$
u_{\Delta}^{\prime}=c_{u_{\Delta}} \Delta_{x}^{3}(\nabla \times \tilde{\mathbf{u}})
$$

where $c u_{\Delta}^{\prime}$ is a model constant. The resolved velocity gradients are felt by the turbulent combustion model through the Smagorinsky subfilter-scale turbulence model and through $u_{\Delta}^{\prime}$. Two important modifications for applications of TFM in engines are to limit the turbulence length 

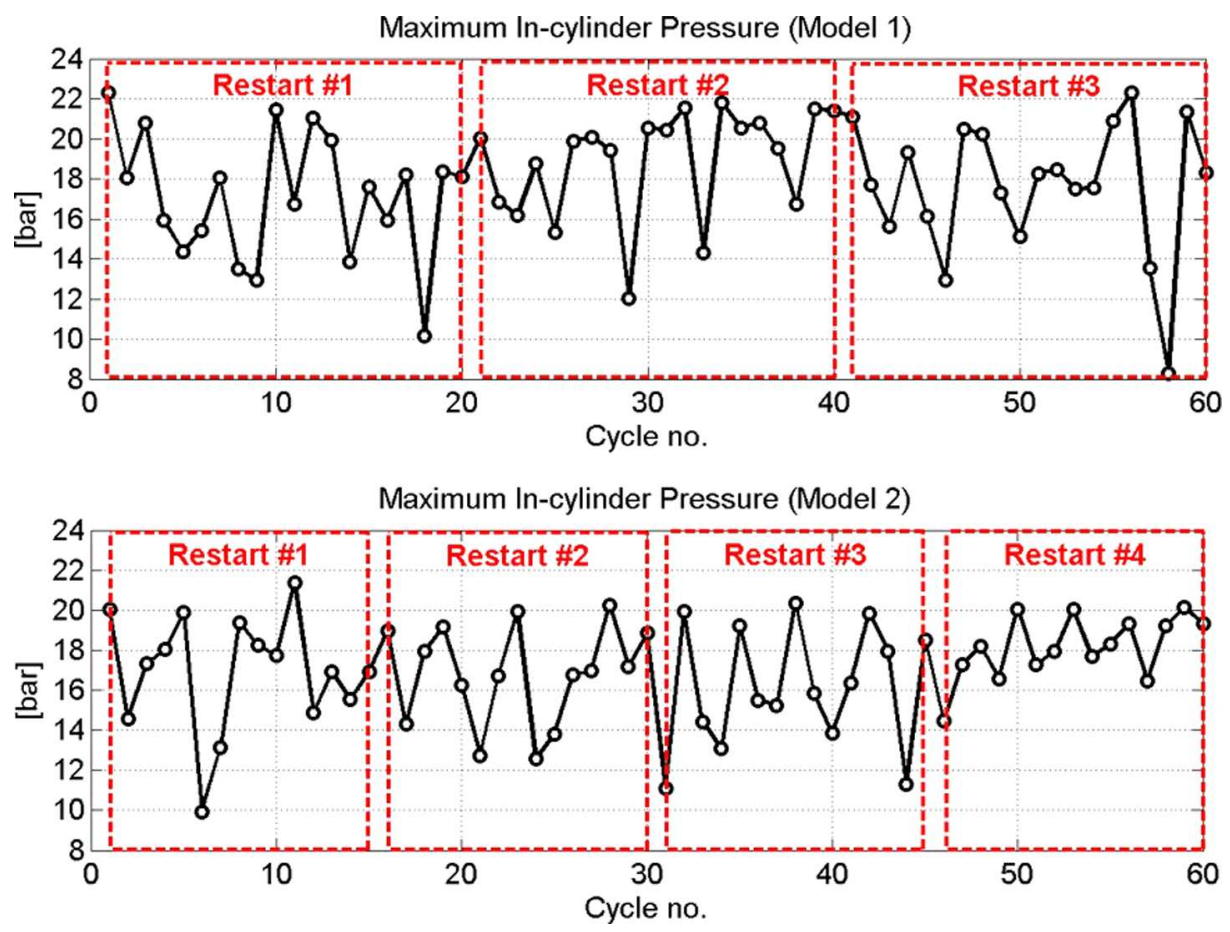

Figure 2

Maximum in-cylinder pressure versus cycle number for Model 1 (top: 3 sets of 20 consecutive cycles) and Model 2 (bottom: 4 sets of 15 consecutive cycles).

scale in vicinity of walls (the length scale cannot be larger than the distance to nearest wall), and to disable the unrealistically high rate of wall heat transfer that is otherwise implied by the model when the flame reaches a wall. Details can be found in [31].

\subsection{Model 2}

Model 2 uses the Imposed Stretch Spark-Ignition Model (ISSIM-LES) [30], implemented in STAR-CD by the authors and coupled with the ECFM-LES turbulent combustion model [32]. The model is based on the theoretical ability of the flame surface density (FSD) approach to account for flame kernel growth to a fully developed flame, from the first appearance of a minimum self-sustained flame nucleus. The simplified model of the coil ignition system from Duclos and Colin [33] is adopted, accounting for electric energy discharge after the breakdown electrode voltage has been exceeded. The electric circuit of the TCC-III engine delivers $36.5 \mathrm{~mJ}$ per cycle, and this value is used in the calculations. The model reproduces the spark-to-gas energy transfer rate in the glow phase as a function of voltage and electric intensity, so that a finite-duration (non-instantaneous) ignition process is simulated. Energy losses to the electrodes lead to an energy transfer efficiency of approximately $60 \%$, following Verhoeven's measurements [34]. Whereas the model for the electric circuit is able to account for re-striking events, no information on this is available from the experiments. The spark plug is fully meshed in the 3D model, and the energy at breakdown is deposited at the midpoint of the electrode gap $(1.15 \mathrm{~mm})$. A corresponding amount of burned gas is initialized, equal to the mass of a cylinder with radius $2 \delta_{l}$, the electrode gap as the initial length and unburnt density $\rho_{u}$. The modeling of a reduced size flame kernel is a challenging task for the FSD-LES equation. For this purpose, a modified FSD-LES equation was proposed in [32]. With $r_{b}$ denoting the burned-gas (flame) radius and $\bar{\Sigma}_{\tilde{c}}$ the flame surface density, the term $\frac{2}{r_{b}}(1+\tau) \Xi S_{L} \bar{\Sigma}_{\tilde{c}}$ accounts for subfilter-scale stretch during ignition. As stated in [30], the hypothesis that the wrinkling factor $\Xi=1$ is made, given the low turbulence intensity at ignition time. The modified FSD-LES equation is:

$$
\begin{gathered}
\frac{\partial \bar{\Sigma}_{\tilde{c}}}{\partial t}=T_{r e s}+T_{s g s}+S_{s g s}+\alpha C_{s g s}-\nabla \cdot\left(\alpha S_{d} N \bar{\Sigma}_{\tilde{c}}\right) \\
+\alpha\left(C_{r e s}+S_{r e s}\right)+(1-\alpha) \frac{2}{r_{b}}(1+\tau) \Xi S_{L} \bar{\Sigma}_{\tilde{c}}+\dot{\omega}_{\Sigma}^{i g n} .
\end{gathered}
$$

The transition from subfilter-scale-only to subfilter-scale and resolved-scale contributions to flame area corresponds to the continuous transition from ignition to a fully propagating turbulent flame. The use of a unique transport equation for FSD from the early stages allows the simulation 
of ignition events occurring in regions of high flow velocity and/or velocity gradients. The transition is governed in the model by an algebraic $\alpha$ function, which depends on the filtered flame radius and is expressed as in equation (7).

$$
\alpha=0.5\left[1+\tanh \left(\frac{r_{b}^{+}-0.75}{0.15}\right)\right], \quad \text { with } r_{b}^{+}=r b / \hat{\Delta}
$$

The flame radius is calculated from the equivalent enflamed spherical volume $V_{b}$. This is defined as shown in equation (8); it is function of the mass-based progress variable $\tilde{c}=1-\tilde{Y}_{F} / \tilde{Y}_{T F}$, where $\tilde{Y}_{F}$ and $\tilde{Y}_{T F}$ are the Favre-averaged concentrations of fuel and fuel tracer:

$$
V_{b}=\int_{c y l} V \cdot \tilde{c} \frac{1+\tau}{1+\tau \tilde{c}} d V
$$

At ignition $(a \cong 0)$, the ignition source term is active and accounts for flame surface production due to subfilter-scale stretch. As the enflamed volume grows and $\alpha$ increases from 0 to 1 , the ignition source term is gradually suppressed, while the $C_{s g s}, \nabla \cdot\left(S_{d} N \bar{\Sigma}_{\tilde{c}}\right), C_{\text {res }}$ and $S_{\text {res }}$ terms are activated. These are the subfilter-scale and resolved-scale curvature, the flame surface density production and the resolved strain contributions to the FSD equation. These terms restore the standard flame-surface-density-based LES turbulent flame propagation equation. The use of a transport equation for the entire flame history starting from ignition allows for full interaction between the local flow conditions (resolved velocity and velocity gradients) and the initial flame growth. The gradient of the resolved velocity $\tilde{u}$ affects the resolved strain $S_{\text {res }}=(\nabla \cdot \tilde{u}-n \cdot \nabla \tilde{u} \cdot n) \Sigma$, while the subfilter-scale velocity fluctuation $u^{\prime}$ is accounted for through the efficiency function $\Gamma\left(\frac{\Delta}{\delta_{l}}, \frac{u^{\prime}}{s_{l}}\right)$ that was proposed in [28], and which is included in the subfilter-scale strain term $S_{\text {sgs }}$. In equation (9), $\Delta$ is the filter length, and $s_{l}$ and $\delta_{l}$ are the laminar flame speed and thickness, respectively:

$$
\Gamma\left(\frac{\Delta}{\delta_{l}}, \frac{u^{\prime}}{s_{l}}\right)=0.75 \cdot \exp \left(-\frac{1.2}{\left(u^{\prime} \cdot s_{l}\right)^{0.3}}\right) \cdot\left(\frac{\Delta}{\delta_{l}}\right)^{2 / 3} .
$$

Finally, a region-specific wall temperature of $1000 \mathrm{~K}$ is imposed for the spark plug metal electrodes, given the impact of heat transfer from the initially small enflamed kernel to the surrounding solid parts.

\section{RESULTS}

The comparisons between experiments and simulations are organized into four subsections: analysis of thermodynamic conditions at time of ignition, analysis based on apparent heat release and related quantities, analysis based on experimental flame imaging and analogous quantities extracted from the simulations, and analysis of the velocity fields in the vicinity of the spark-plug gap at the time of ignition.

\subsection{Thermodynamic Analysis}

The first comparison between experiments and simulations is the thermodynamic state of the mixture at SOIgn, $342^{\circ}$ aTDCe. The $\log P-\log V$ plots of Figure 3 show 60 cycles of experimental data and 60 cycles from each model through compression, combustion and expansion. This provides a comparison of the volume-averaged thermodynamic states experienced in the experiments versus those experienced by the two models. Looking first at the compression stroke, it can be seen that there is imperceptible $\mathrm{CCV}$ in both the measurements and the simulations, and that the measured data suggest a larger value for the polytropic coefficient $n$ compared to the models: $n_{\text {Meas }}=1.33, n_{\text {Mod1 }}=$ $1.31, n_{\mathrm{Mod} 2}=1.31$. There is very little droop in the expected straight lines, as indicated by the very high values of the measured and simulated $R^{2}$. The lower polytropic coefficients for the LES can only be caused by different trapped mass or by heat loss, since there is no blow-by in the LES and the air/fuel composition is well known. The unknown temperature of the quartz cylinder in the experiments and uncertain wall-heat-transfer model in the LES are the most likely reasons for the disagreement between the measured and simulated polytropic coefficient values. It can be estimated from the polytropic compression that this difference in the values of $n$ would result in a $6 \%$ lower bulk temperature for the LES compared to experiment (out of approximately $600 \mathrm{~K}$ ) at SOIgn $=342^{\circ}$ aTDCe.

The pressure CCV near TDC are also revealed in Figure 3. From these, it can be seen that some of the LES cycles burn quite late, and that in turn yields higher CCV in the expansion stroke in the simulations compared to the experiments.

\subsection{Apparent Heat Release Analysis}

The combustion variability is more evident in Figure 4, where measured and computed Apparent Heat Release Rate (AHRR) traces are compared. There, 60 measured cycles are shown, so that the sample size is the same as in the simulations. It will be shown later that these 60 measured cycles are representative of the 1500 total available experimental cycles (500 cycles each from three separate tests). The measured results in Figure 4 show that combustion has completed by $30 \mathrm{CAD}$ after TDC for all cycles. This was suggested by Ayala and Heywood [4] to be a necessary condition for stable engine operation. Both LES models exhibit longer combustion durations and higher 

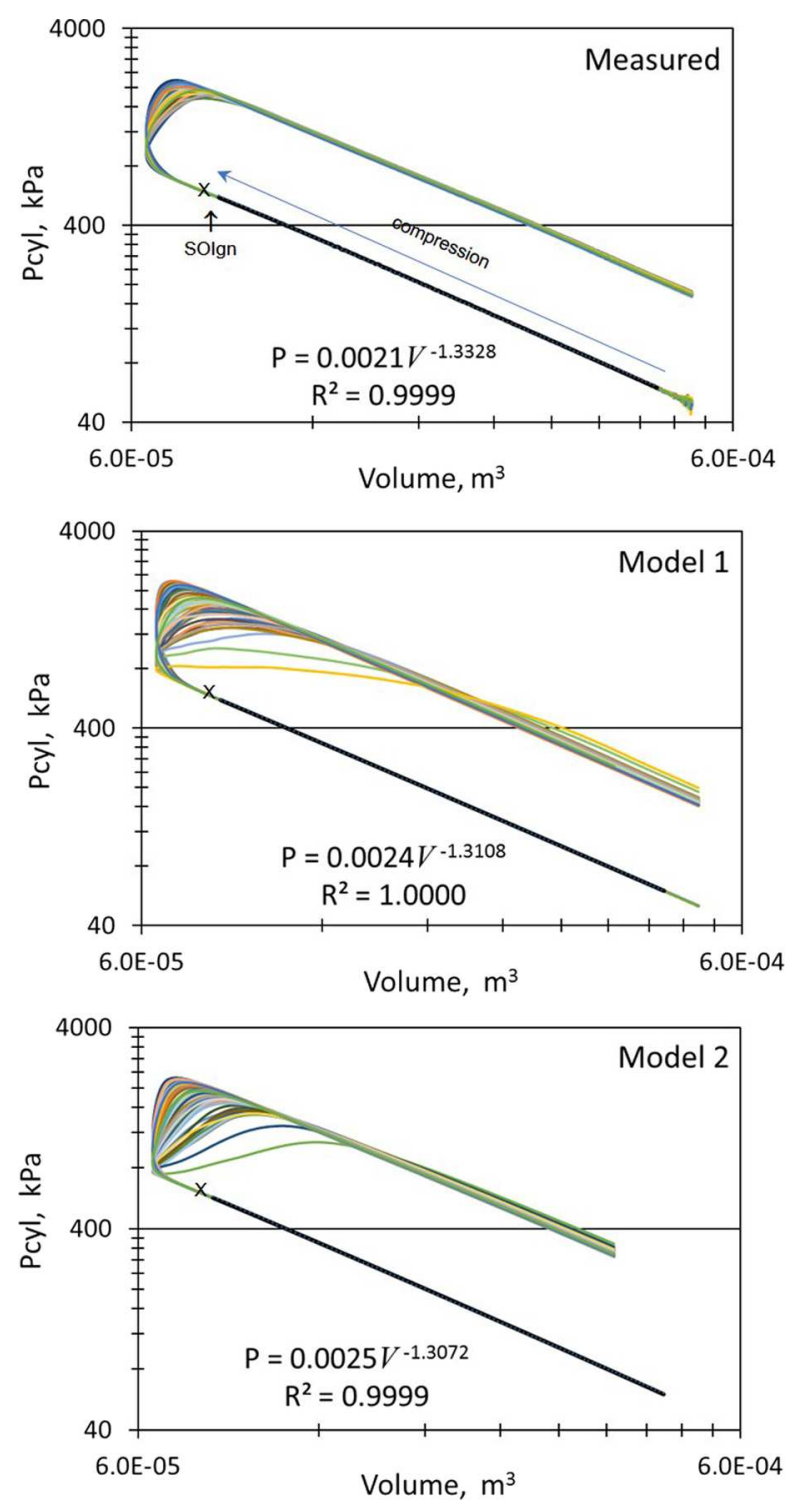

Figure 3

$\log P$ versus $\log V$ diagrams of the compression, combustion and expansion strokes for the measured data (top), Model 1 (center) and Model 2 (bottom).

$\mathrm{CCV}$ compared to what is observed in the experiments. In particular, the simulations (especially Model 1) show some extremely slow cycles that are not seen experimentally for this operating condition.

It is customary to use the MBF obtained from the pressure-based cumulative AHR, to quantify the 10-, 50- and 90-percent MBF periods (CA10, CA50 and CA90). Figure 5a compares the individual-cycle MBF based on the cumulative AHR with the MBF based on the actual fuel consumption for LES Model 1, and Figure 5b shows the corresponding CA10, CA50 and CA90 values. Results for Model 2 are similar (not shown). Together, Figure $5 \mathrm{a}$ and $\mathrm{b}$ demonstrate that the pressure-based AHRR analysis of equation (1), which
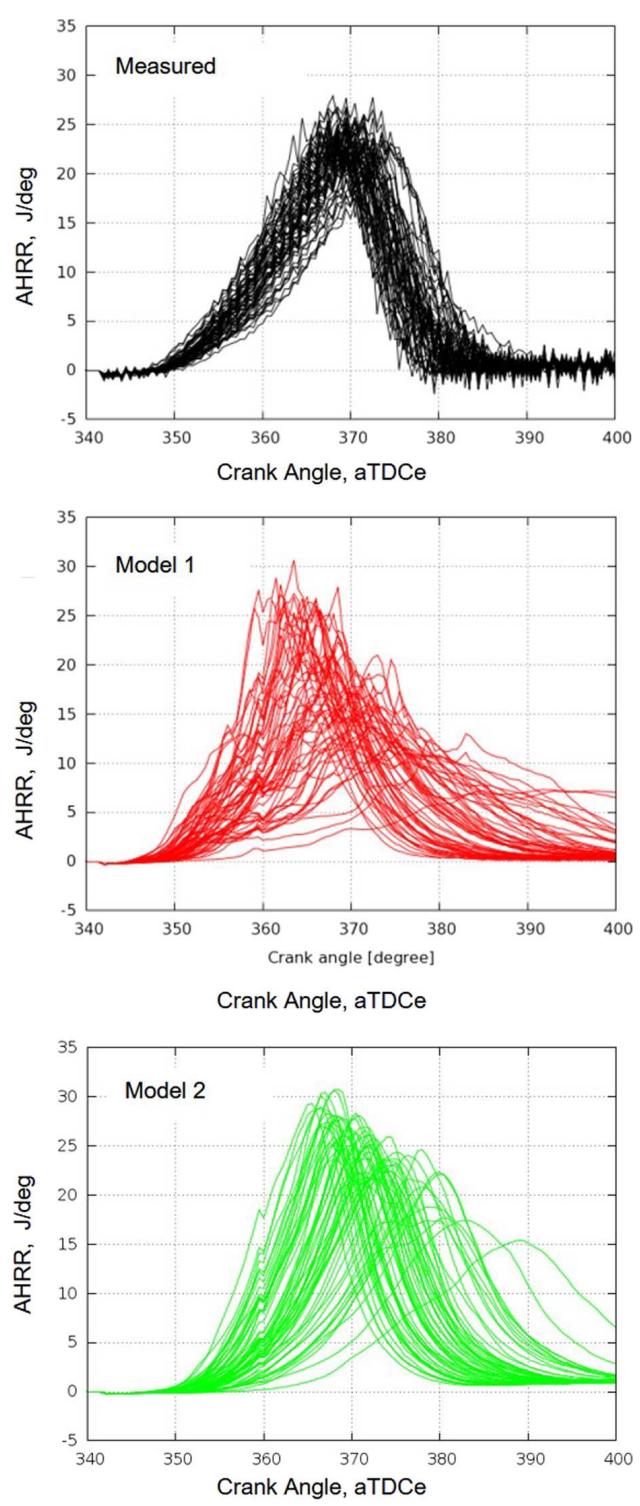

Figure 4

Measured and computed individual-cycle AHRR versus crank angle. Top: measured. Center: Model 1. Bottom: Model 2.

has typically been applied to experimentally measured data, is a precise metric that accurately reflects the actual fuel burn rate. It is therefore useful as a single metric that can be applied to both the measured and simulated data.

Figure 6 shows the range of $\mathrm{CA} 10 \mathrm{CCV}$, and the correlations between CA50, CA90, and the Location of Peak Pressure (LPP) with CA10. Linear correlations of CA50, CA90 and LPP with CA10 are evident in both the experiments and the LES. The experiments exhibit a consistently smaller range of values for CA10 and CA90 (lower CCV) compared to the simulations. However, in all cases the burning after CA50 becomes more variable, as indicated by the lower correlation of CA10 with CA90 


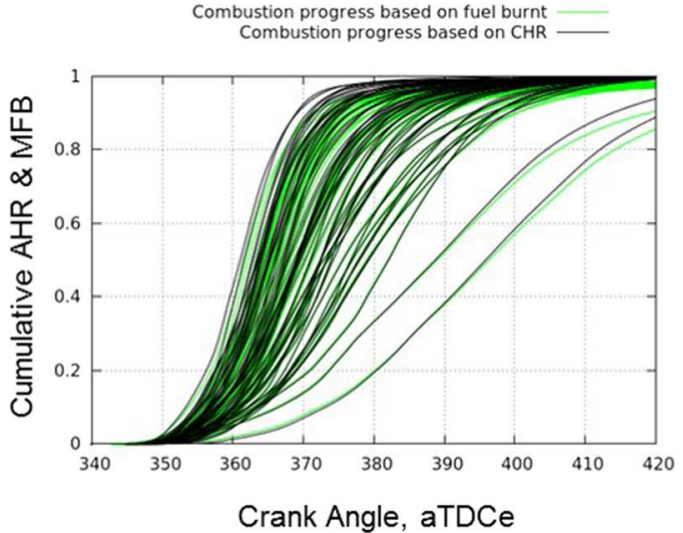

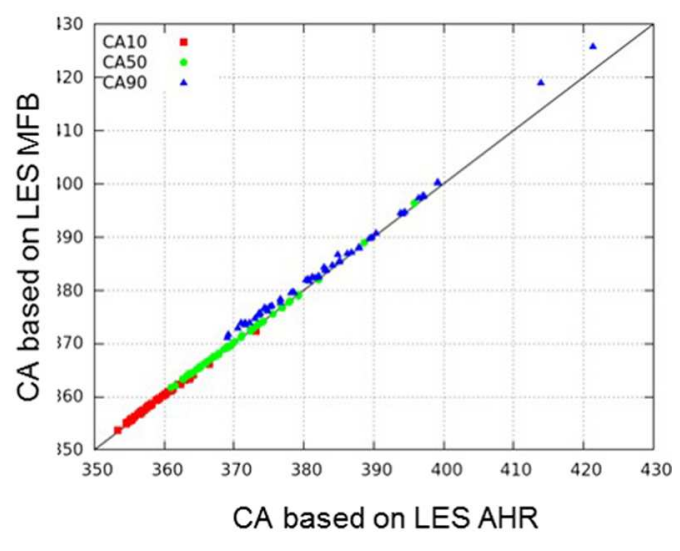

b

Figure 5

Comparisons of MBFs based on the cumulative AHR versus on the fuel consumption rate, for Model 1.

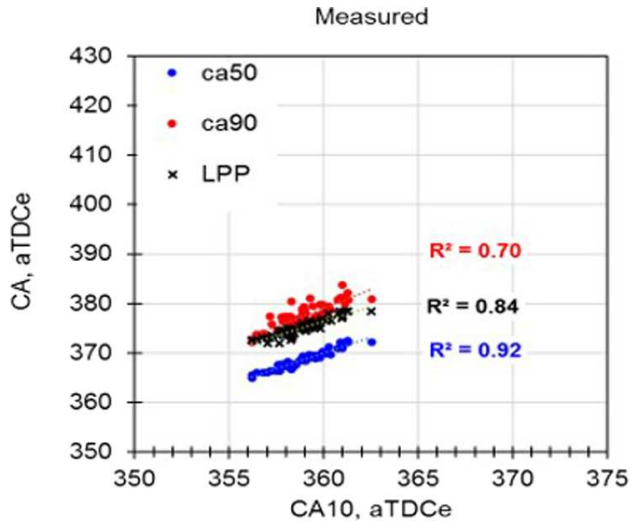

a)

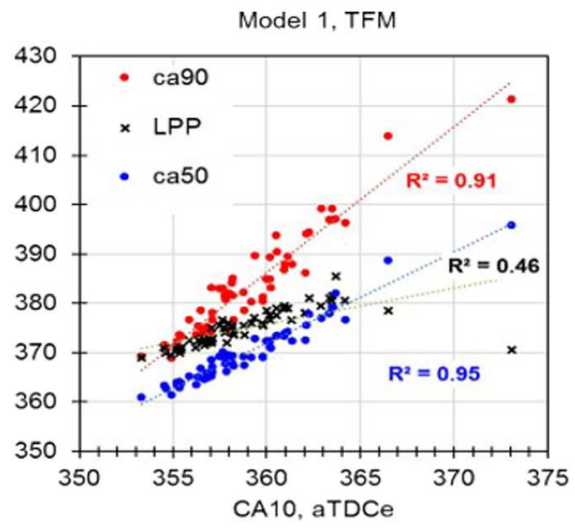

b)

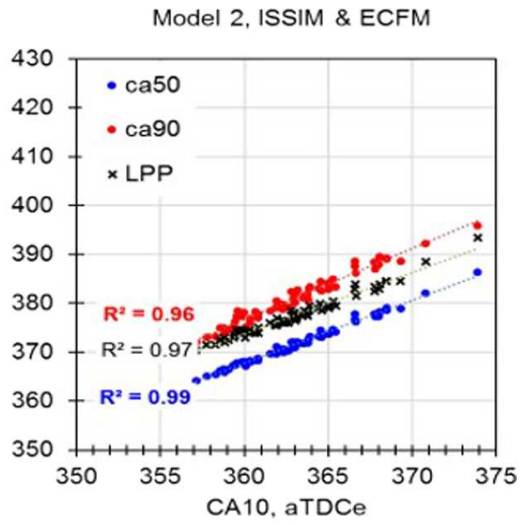

c)

Figure 6

Scatter plots of CA50, CA90 and Location of Peak Pressure (LPP) versus CA10. Left: Measured. Center: Model 1. Right: Model 2.

compared to CA50. Although the ranges of the values from the simulations overlap with the measured values, it is clear that both models exhibit some cycles with considerably slower burns compared to the measurements. More importantly for the present purposes, Figure 6 demonstrates that the CCV of combustion is highly correlated with the early flame kernel development time, even for the very-lateburning simulated cycles (evident from the $R^{2}$ values). Therefore, it is essential to correctly capture the early flame development period in the simulations, and to better understand what is happening during this critical period. The subsequent comparisons between experiments and simulations focus on the early flame development.

While it is possible to compute the AHRR from measured pressured data prior to CA10, experimental values of AHRR at very early times can be unreliable because of inaccuracies and low signal-to-noise ratios. Figure $7 \mathrm{a}$ shows this breakdown for the very early burn
(CA005). Figure $7 \mathrm{~b}$ shows that CA01 correlates linearly with CA10 in both the experiments and the simulations. As already noted, the experiments are difficult for very early times. And in the LES models used here, factors such as discharge repeatability and heat transfer to electrodes, are not fully taken into account; therefore, a correlation between CA01 and CA10 might be expected in the simulations, to some extent. The arbitrary imposition of a cycle-independent ignition energy might reduce the CA01/ CA10 correlation, but possibly for the wrong reason. With these caveats, the results suggest that the phasing of CA10 (and from what has been shown earlier, the phasing of the entire combustion event) has largely been established by CA01 for this operating condition. Thus, it is of interest to explore additional measures to dissect the ignition and flame propagation processes prior to CA01. For this purpose, flame imaging was used to capture the early-flame 


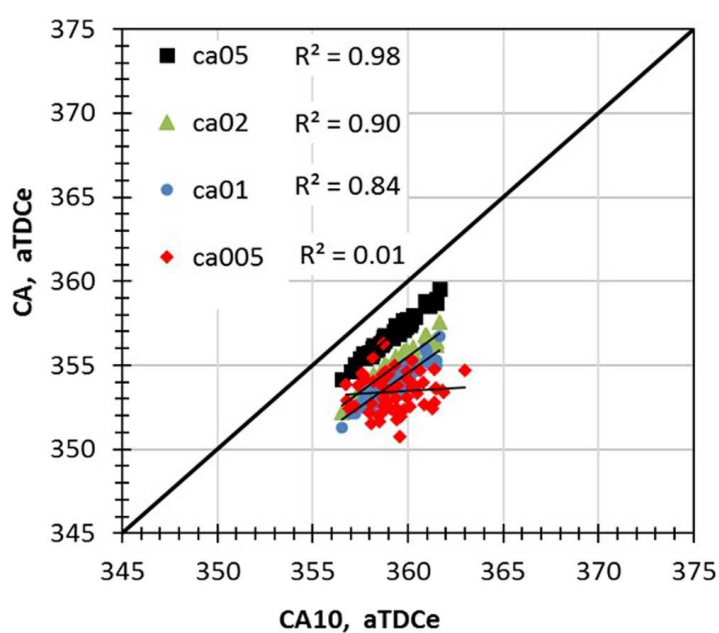

a)

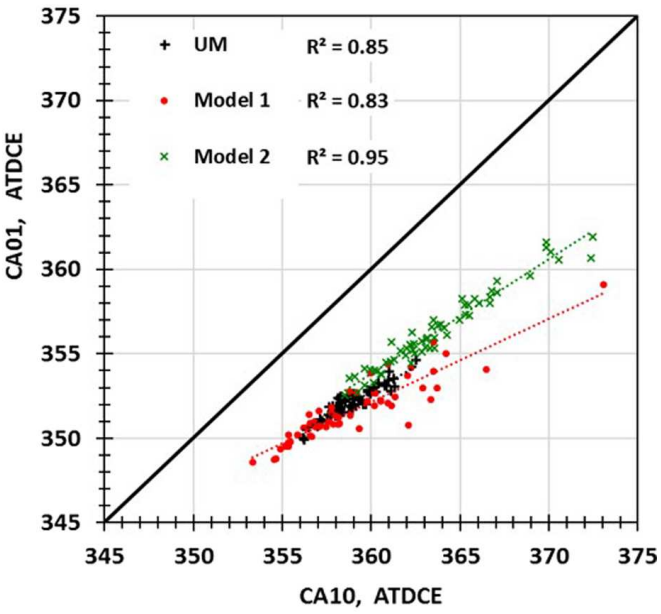

b)

Figure 7

(a) Measured MBF at crank angles prior to CA10, demonstrating limitations of pressure-based AHRR analysis prior to CA01. (b) Comparisons of CA01 and CA10 distributions between simulated (Model 1 and Model 2) and measured (labeled "UM") cycles.

growth, and to estimate the notional laminar-to-turbulent transition time, $\tau_{\text {lam-turb }}$, suggested by Abraham et al. [17], as described in the following subsection.

\subsection{Flame Imaging Analysis}

The flame growth was quantified here as the projected $2 \mathrm{D}$ area of the 3D burned-gas volume, as measured from the $\mathrm{OH}^{*}$ images and the simulations (Fig. 8a) every 2 CAD. For the projected flame area in the simulations, the 3D flame surface was defined as the location of $50 \%$ local mass burned fraction, and the 2D projected area was computed as in the experiments. This is a somewhat less-than-perfect comparison between experiments and simulations, because of the missing out-of-plane flame-growth information. Nevertheless, it is of interest to see whether or not this relatively simple approach reveals anything of interest. Applying the concept of Arpaci et al. [18], the transition time $\tau_{\text {lam-turb }}$ is defined here as the time between SOIgn and $\max \left(d^{2} A_{f l m} / d t^{2}\right)$, as shown in example of Figure 8b; therefore the roll-off of the flame growth after $1 \mathrm{~ms}$ is due to the limited experimental field of view. Figure $8 \mathrm{c}$ shows that this transition occurs well before CA01.

It is recognized that the single view that is available experimentally is limited in its ability to capture out-of-plane growth, for example. However, this metric is intended only to identify the overall growth rate, not the absolute volume. This metric was found to correlate with CA10 and to discriminate between the stoichiometric and rich/lean/dilute mixtures of the experimental measurements of Schiffmann [7]. Figure 9 shows that there is a weak linear correlation between $\tau_{\text {lam-turb }}$ and CA10 (the bimodal distribution of growth rates is believed to be an artifact of the low sampling rate (2 CAD) compared to the growth rate). This may be due to multivariable influences as well as the single view of the measurement. Nonetheless, $\tau_{\text {lam-turb }}$ identifies the transition from one growth rate to another, and in principle can be applied equally to both the measured and simulated data. However, a sharp transition in growth rate was not observed in the simulations for either model (not shown).

To further dissect the EFD period, the measured cycle-tocycle spark-duration distribution is compared to the measured duration of CA10 (CA00-CA10) in Figure 9. The plasma duration distribution is presented here as a reminder that both electrical and chemical energies contribute to the early flame kernel during this period. Figure 9 demonstrates that the glow-discharge ignition system used here creates a plasma whose duration is longer than $\tau_{\text {lam-turb, and that it lasts until nearly CA10. This }}$ suggests that the flame growth measured by the $\mathrm{OH}^{*}$ emissions have commenced well before the plasma has ended. Furthermore, neither spark duration nor $\tau_{\text {lam-turb }}$ correlate strongly with CA10. This figure also illustrates that the 60 measured cycles that were selected to compare with the 60 computed cycles from each model are representative of the 1500 available measured cycles.

A length scale that is expected to be relevant for the early flame development is computed as the diameter of a circle that has the same projected 2D area as that of the flame kernel. Figure 10 shows the ensemble-averaged equivalent diameter of the flame as a function of time after start of ignition, for the experiments and the two LES models. The range of the $\mathrm{CCV}$ in this quantity (dotted lines) is quantified by the minimum and maximum areas observed in the three data sets. Also shown are the average values of $\tau_{\text {lam-turb, }}$ CA01, End of Spark (EoSpk), and CA10. From this figure, 


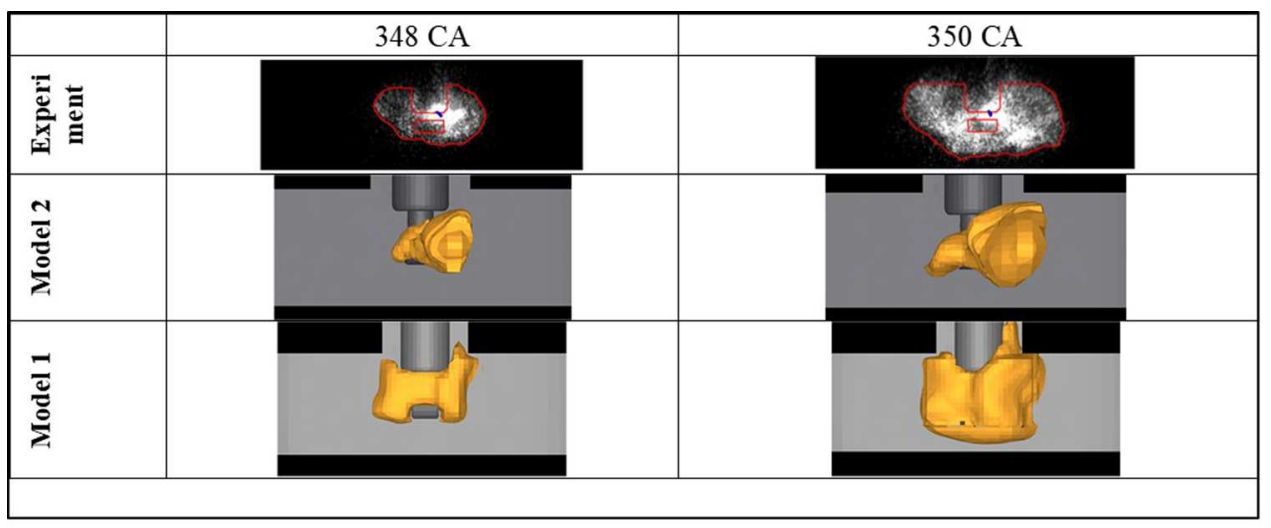

a)

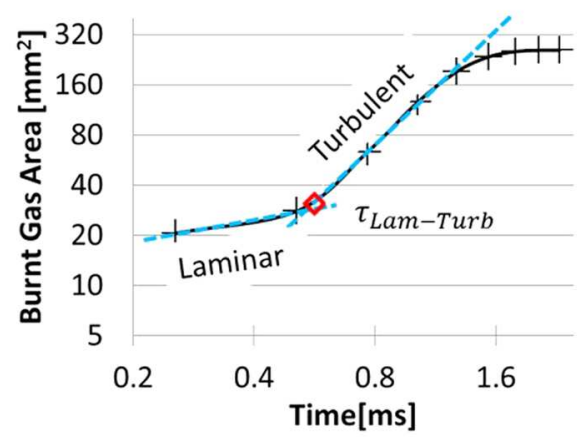

b)

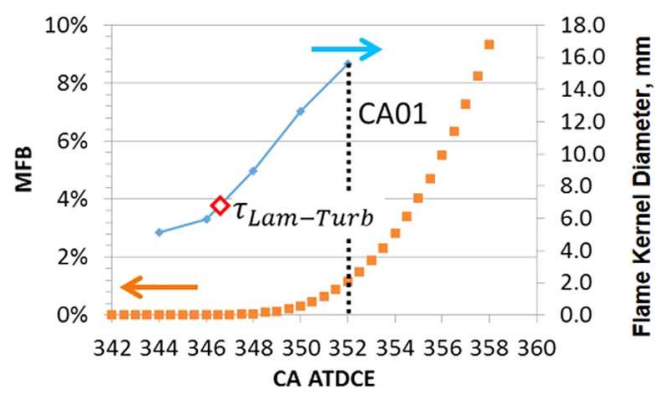

c)

Figure 8

(a) Examples of measured and simulated 2D projected flame kernel area. A single-cycle example of the burned-gas area evolution for a measured cycle is used to quantify the laminar-turbulent transition time, $\tau_{\text {lam-turb }}$, shown by the red-diamond in (b), which occurs much earlier than the $1 \%$ MBF from the AHR analysis (c).

estimates of the relevant flame-kernel length- and timescales during the period between SOIgn and CA10 can be deduced. Since $\tau_{\text {lam-turb }}$ has been shown to be poorly correlated with CA10, while CA01 is highly correlated with CA10, it can be deduced that the correlation with CA10 develops in the period between $0.4 \mathrm{~ms}$ and $1.5 \mathrm{~ms}$ (CA01), where the flame diameter is between 5 and $15 \mathrm{~mm}$. This can be compared to the estimated integral time scales of 1-1.3 ms and integral length scales of $L_{\mathrm{ux}}, L_{\mathrm{uz}}, L_{\mathrm{wz}}$ and $L_{\mathrm{wx}}$ equal to $10-20 \mathrm{~mm}, 8 \mathrm{~mm}, 3 \mathrm{~mm}$ and $5 \mathrm{~mm}$, respectively [7], where $L_{i, j}$ denotes the correlation length for the $i$ th velocity component in the $j$ th direction. This then suggests that simulated and measured flow properties at these scales could be compared, to develop further insight into the early flame development.

\subsection{Local Flow at Spark Gap Analysis}

Comparisons between computed and measured mean and rms velocity fields for motored and firing conditions are reported in [31], and the reader is referred there for detailed quantitative comparisons. An example of mean velocity fields on two cutting planes that pass close to the spark gap at an instant shortly before SOIgn are shown in Figure 11, to give a general impression of the large-scale flow structure. There are quantitative differences between the two LES models, between LES and PIV, and between the motored and firing pre-ignition flow fields, but the general flow patterns are similar.

Multiple earlier experimental and simulation studies have shown that local flow conditions in the vicinity of the spark gap at the time of ignition affect the early flame kernel development and subsequent combustion process [7-13]. In particular, flame plasmas and kernels can be advected away from the spark plug, which affects the combustion phasing. Thus, it is prudent to compare not only the thermodynamic state between the experiments and simulations at the time of ignition (Fig. 3), but also the velocity and velocity gradients. Scatter plots of velocity magnitude, $|V|$, and the direction of the velocity in the 2D measurement plane (Fig. 1), $|u|$ and $|w|$, are shown in Figure 12. Both the measured and simulated values have been spatially averaged over the $12 \mathrm{~mm} \times 6 \mathrm{~mm}$ region illustrated in Figure 1. Therefore, these represent low-pass spatially filtered values (over a spatial scale of $\sim 10 \mathrm{~mm}$ ) in the vicinity of the spark plug. As noted earlier, 


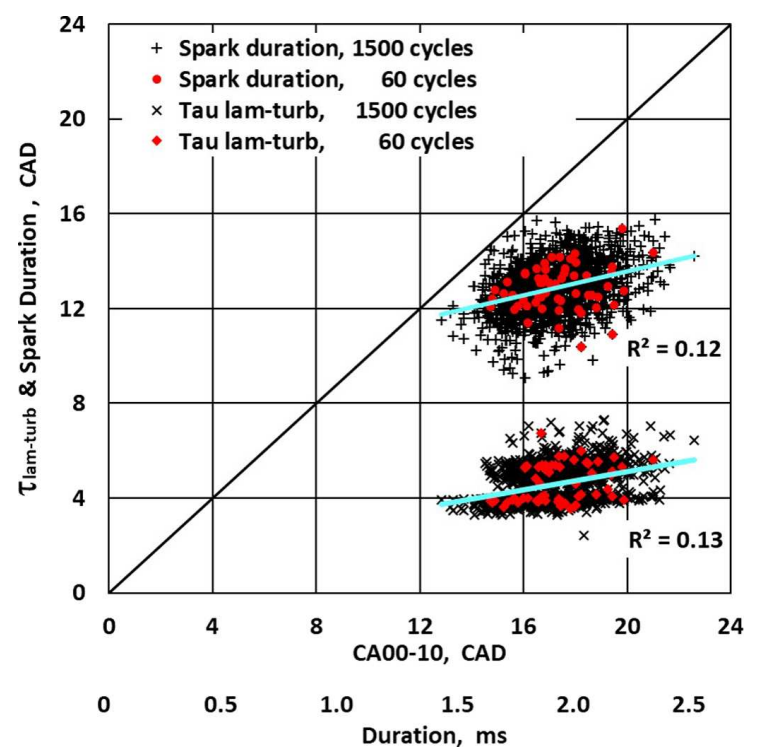

Figure 9

Measured spark-discharge duration and $\tau_{\text {lam-turb }}$ distributions from 1500 cycles ( 500 cycles from each of three independent tests - in black), and the 60 sampled cycles (in red) that are used to provide a sample size that is the same as that available from the simulations.

the measurement plane does not pass directly through the spark-plug gap (it is offset by $4.5 \mathrm{~mm}$ ). Nevertheless, the measured values of $|V|$ were found to correlate with CA10 in the statistical analysis of Schiffmann [7]. This offset does not detract from the point of the comparison here, which is to determine whether or not the simulations are predicting similar velocities near the spark plug. Figure 12 shows that the range of $|V|$ values from the simulations tend to lie within the lower half of the measured range of values. Furthermore, the direction of the large-scale flow (as indicated by the trend in the $|w|$ versus $|u|$ plot) is consistent between the experiment and simulations, although again, the overall lower velocity magnitudes in the simulations are evident.

Since Figure 12 demonstrates that there are differences between the measured and simulated large-scale velocity magnitudes near the spark plug, it is reasonable to assess if the measured and simulated resolved-scale velocity gradients are similar or significantly different. The resolvedscale velocity gradients play an important role in subfilterscale turbulence and turbulent combustion modeling, as discussed earlier in the modeling section. In Figure 13, measured and computed distributions of the two-component resolved-scale velocity gradient components over the $12 \mathrm{~mm} \times 6 \mathrm{~mm}$ measurement region displaced $4.5 \mathrm{~mm}$ from the spark-plug gap (the same region for which area-averaged velocities are shown in Fig. 12) are plotted. These distributions were sampled for all 60 simulated cycles and for the 60 representative measured cycles. The measured (PIV) velocity gradients were computed directly from $1 \mathrm{~mm}-$

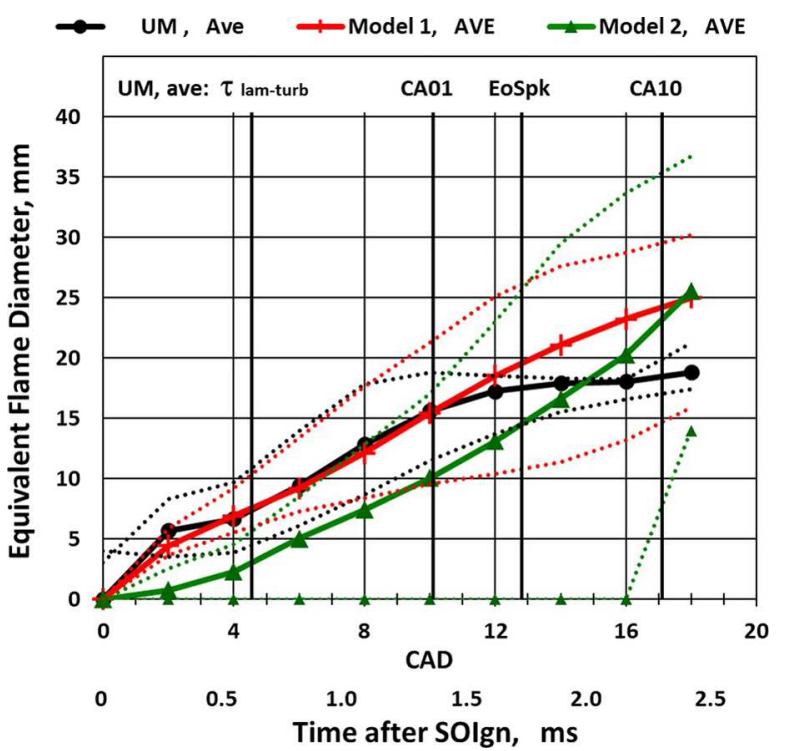

Figure 10

Ensemble-averaged (solid lines) and cycle-to-cycle range (dotted lines) of the flame's equivalent diameter for all measured (1500) and simulated (60 each) cycles. The vertical lines mark crank angles of interest, from which the temporal and spatial scales of the early flame-kernel growth can be deduced.

resolution interrogations spots on a $0.5 \mathrm{~mm}$ grid, whereas the simulation distributions were sampled on the computationalgrid and subsequently mapped onto the PIV grid. The most striking feature of Figure 13 is the significantly narrower distribution of measured velocity gradient values compared to the simulated velocity gradient values.

To assess if the larger gradients from the simulations are the result of higher computational-grid resolution compared to the experimental spatial resolution, a linear correlation was performed between the gradients mapped from the computational grid to the PIV grid and gradients computed from the remapped computed velocities. The linear correlation demonstrated that the gradients computed from the remapped velocity were only $8 \%$ lower than the higher-resolution simulation gradients, with a linear correlation coefficient of 0.98 . Thus, it was concluded that the narrower distributions of the measured gradients are not due to the remapping. Rather, Figure 13 reveals the limited ability of PIV measurements to resolve steep gradients. This may be the result of three factors: the error between the particles' motion and the local gas-phase flow velocity; the limited dynamic range of the instantaneous velocity measurements $(0.2$ pixels out of $8=40 \times)$; and the difficulty of PIV-correlation-based peak-detection in regions of steep velocity gradients (vector drop out). Thus, based on these measurements, it is not possible to conclude if the simulations accurately predict the resolved-scale gradients in the flow. Nevertheless, since the two LES models yielded different combustion phasing (e.g., Fig. 4), it is of value to compare the computed gradient distributions between the two models. 


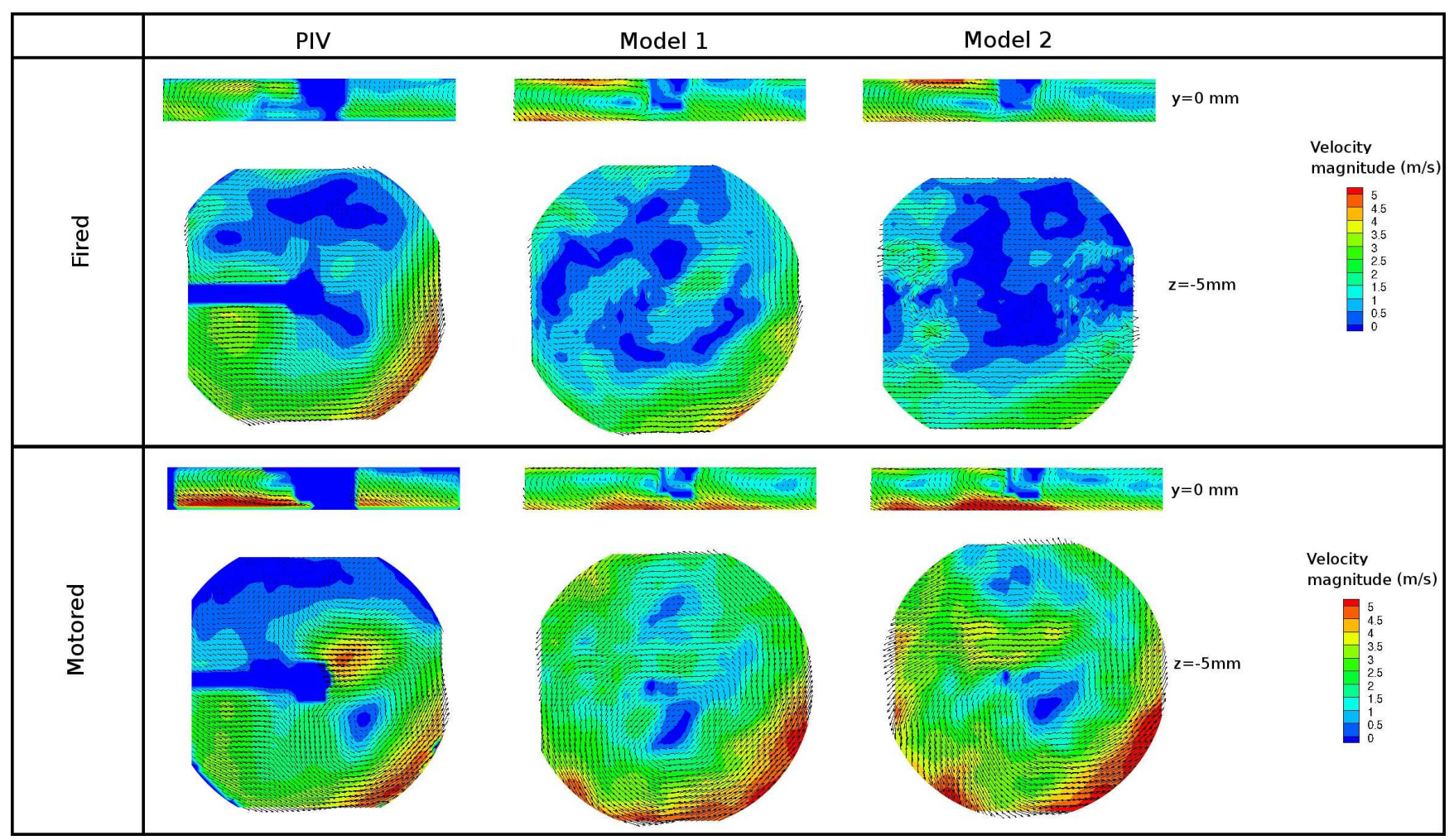

Figure 11

Comparisons between measured and simulated mean velocity fields on two cutting planes at $340^{\circ} \mathrm{aTDCe}\left(2^{\circ}\right.$ before SOIgn).

To assess the velocity-gradient distributions that the LES models present to the ignition/combustion models, all nine velocity-gradient-tensor components were sampled and compared from the two simulations in a three-dimensional volume around the spark plug at the time of ignition. The distributions were sampled from all 60 cycles, on a $0.5 \mathrm{~mm}$ grid in a rectangular prism volume centered at the sparkplug gap: $x=-8 \mathrm{~mm} \rightarrow 4 \mathrm{~mm}, y=-4.5 \mathrm{~mm} \rightarrow 4.5 \mathrm{~mm}$, $z=-8 \mathrm{~mm} \rightarrow-2 \mathrm{~mm}$. In addition, the distributions from the 10 fastest burning and 10 slowest burning cycles are plotted in Figure 14. These distributions are the fraction of the total sample in the histograms (bin size of $2501 / \mathrm{s}$ ) normalized by the number of samples. Thus, the fraction of the total sample (370k samples) can be compared to the $37 \mathrm{k}$ samples of the 10 fastest and slowest cycles, respectively. The distributions displayed in Figure 14 show that Model 2 has more low-magnitude gradients $(-1000 / \mathrm{s}$ to $+1000 / \mathrm{s})$ compared to Model 1; Model 1 yields broader distributions with larger excursions from the mean. Figure 14 also shows slight variations in skewness between the two simulations. As demonstrated by Petersen and Ghandhi [35], the turbulent dissipation in engine flows is expected to occur in relatively localized high-shear regions between larger structures. Thus, the occurrence of the largest gradients from Eulerian measurements is expected to be infrequent compared to the smaller magnitude gradients at the interior of the larger structures. This is consistent with the distributions in Figure 14.

To better reveal the large dynamic range and relative frequency of occurrence of high-magnitude gradients, it is of value to replot the fractional frequency in Figure 14 using a logarithmic scale (Fig. 15). Figure 15 more clearly reveals the comparatively smaller range of velocity gradients presented to the ignition and turbulent combustion models by Model 2 compared to Model 1 . The reason for this difference is unclear, at this point. It is perhaps more revealing to compare the fastest and slowest cycles from each model. Figures 14 and 15 show that for both models, the slowest cycles correspond to a narrower distribution of velocity gradient magnitudes (fewer samples with high velocity gradient magnitudes) compared to the mean distribution, while the fastest cycles correspond to a broader distribution of gradient magnitudes (more samples with high velocity gradient magnitudes) compared to the mean. Higher velocity gradients may lead to accelerated flame growth, and exposing the early kernel to a broader range of fluctuating velocity gradients may also contribute. Conversely, lower velocity gradient fluctuations and the absence of high velocity gradient magnitudes result in slower early flame growth. 

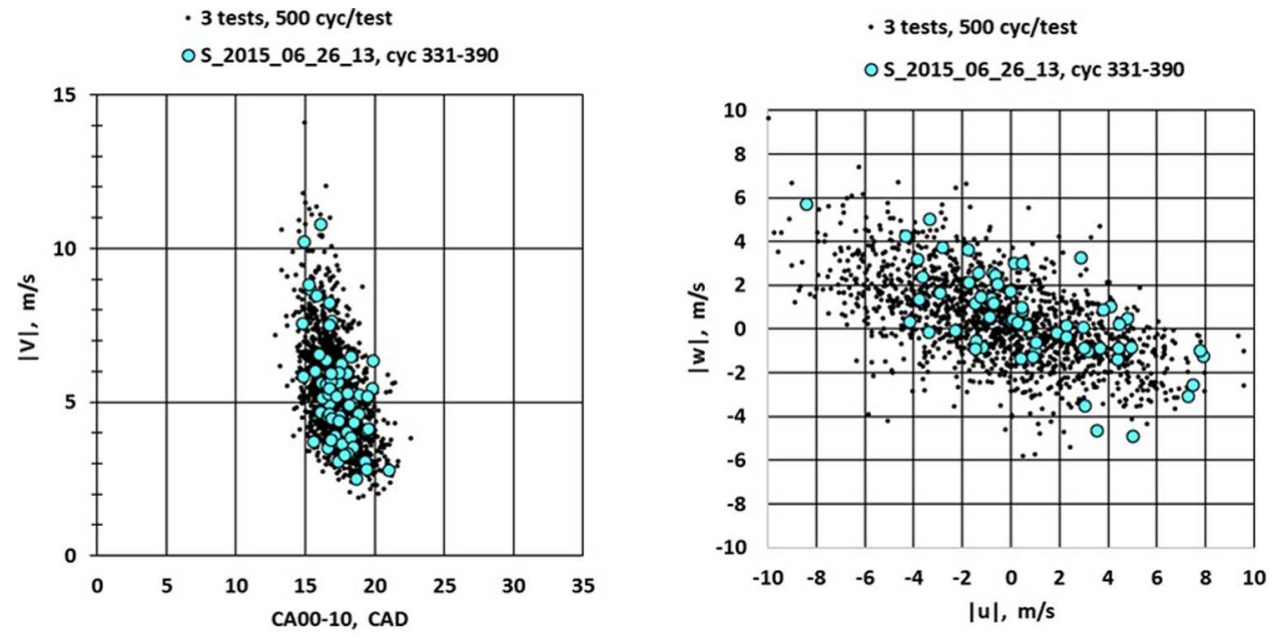

Model 1

Model 1
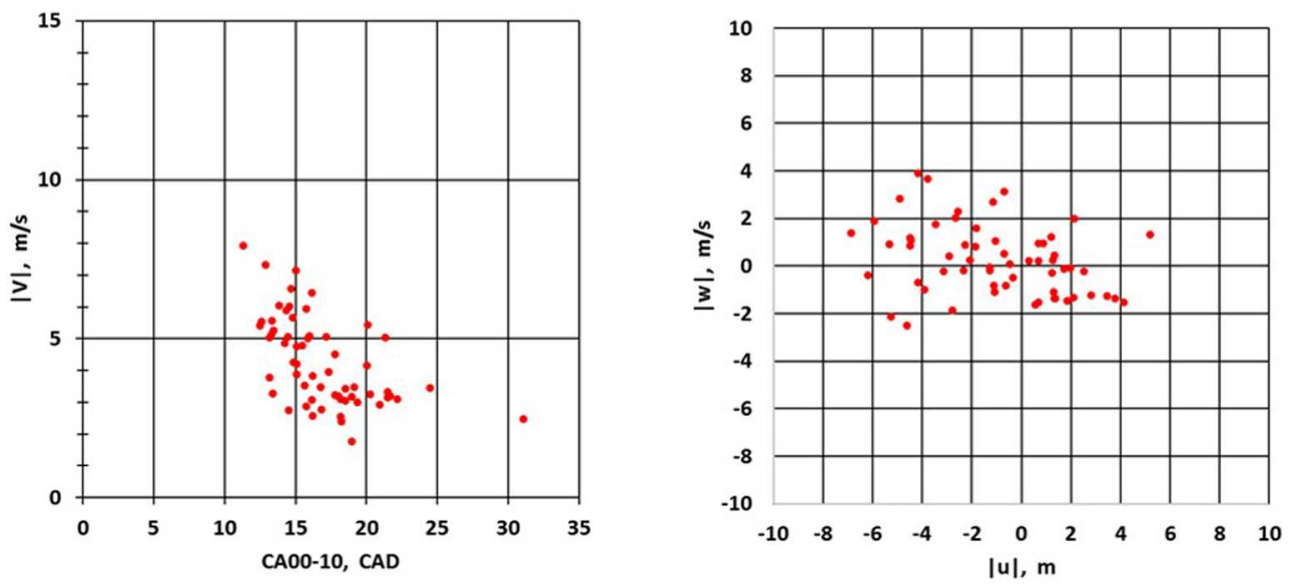

Model 2

Model 2
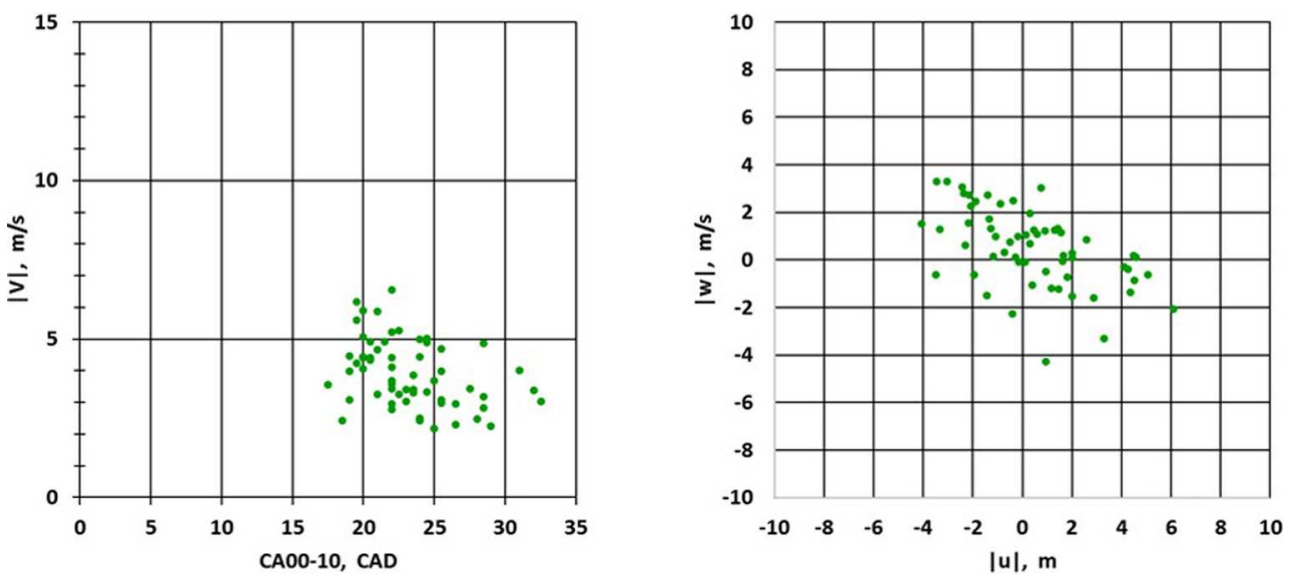

Figure 12

Comparisons between measured and simulated velocity magnitude $|V|$ distributions with the duration of CA10 (left), and 2D velocity components $|u|$ and $|w|$ showing distribution of the velocity direction (right). In all cases, the velocities have been spatially averaged over a $12 \mathrm{~mm} \times 6 \mathrm{~mm}$ region in the vicinity of the spark-plug gap ( $y=-4.5 \mathrm{~mm}$, Fig. 1$)$ at SOIgn $\left(342^{\circ} \mathrm{aTDCe}\right)$. For the experiments, all 1500 cycles and 60 representative cycles are shown, the latter to provide a clearer visual comparison with the 60-cycle LES results. 
Measured, PIV-Mask, $y=-4.5$

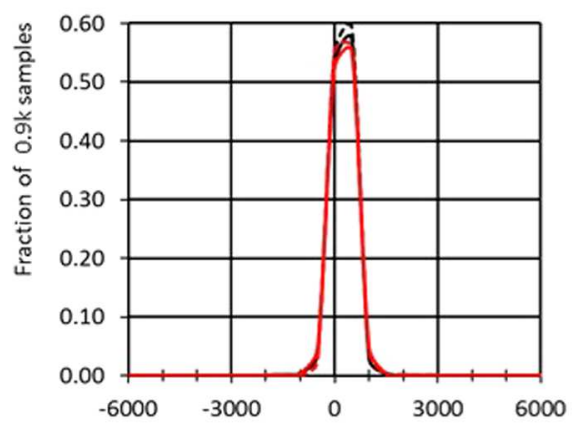

Model 1, PIV-Mask, $y=-4.5$

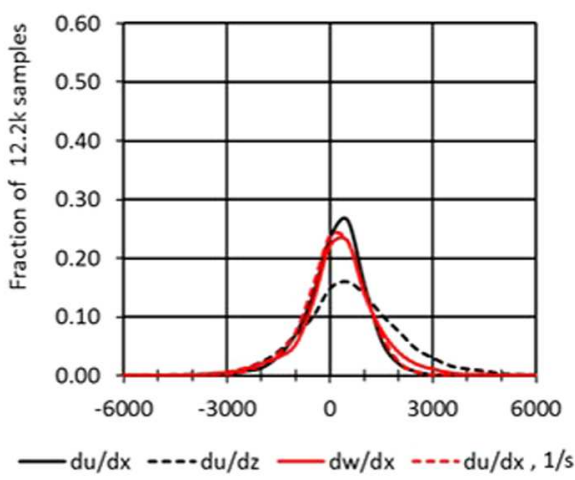

b
Model 2, PIV-Mask, $y=-4.5$

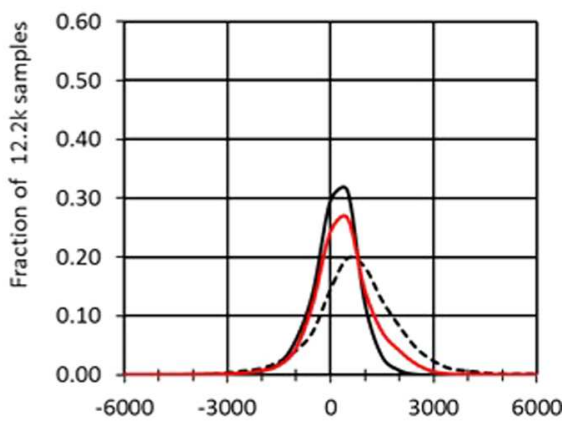

C

Figure 13

Measured and computed two-component velocity gradient distributions in a measurement region in the vicinity of the spark plug (Fig. 1) at SOIgn $\left(342^{\circ}\right.$ aTDCe). Distributions of all four $2 \mathrm{D}$ velocity gradient components are shown.

\section{CONCLUSION}

Pressure-based combustion analysis, optical diagnostics and LES have been used to generate new physical insight into the early stages of combustion in homogeneous-charge sparkignition engines. The emphasis has been on developing strategies for making quantitative comparisons between high-speed/high-resolution optical diagnostics and LES using common metrics for both the experiments and the simulations, focusing on the important early flame development period.

These are the first comparisons between combustion LES and experiments for the TCC engine, an engine configuration that is freely accessible to other research groups. Results from two different LES ignition turbulent flame propagation models have been presented, using the same numerical methods and computational mesh. The results reveal strengths and limitations of the experimental diagnostics and LES models. Specific findings are as follows:

- Local flow conditions in the vicinity of the spark gap at the time of ignition play a significant role in determining the subsequent combustion event for the cycle. This largely confirms results from multiple earlier experimental and simulation studies.

- Two widely used LES models yield rather different combustion behavior compared to experiments. Both models show somewhat lower velocity magnitudes in the vicinity of the spark gap at the time of ignition compared to experiment, and both models show higher combustion CCV compared to experiment. In particular, the models give some very slow-burning cycles that are not observed in the experiments. Nevertheless, the comparisons between models, and between models and experiments, provide useful insight into the early flame development and into the limitations of the models and the experiments.

- In the simulations, fast-burning cycles correspond to cycles where there is a broader distribution of velocity gradient magnitudes (more samples with high velocity gradient magnitudes) in the vicinity of the spark-plug gap at the time of ignition compared to the average distribution. Conversely, slow-burning cycles correspond to cycles where there is a narrower distribution of velocity gradient magnitudes in the vicinity of the spark-plug gap at the time of ignition compared to the average distribution. Higher velocity gradient magnitudes may lead to accelerated flame growth, and exposing the early kernel to a broader range of fluctuating gradients may also contribute. To explore this experimentally, it will be necessary to modify the PIV technique that has been used here to better resolve steep local velocity gradients.

- The fate of the combustion event for each cycle is largely determined by what happens between the laminar-toturbulent transition time and CA01. This suggests a range of temporal and spatial scales over which subsequent comparisons between experiments and simulations should be performed.

\section{ACKNOWLEDGMENTS}

Coauthors from the Pennsylvania State University and the University of Michigan gratefully acknowledge funding from GM Global R\&D. Coauthors from the Pennsylvania State University and the University of Modena and Reggio Emilia gratefully acknowledge Siemens PLM Software for providing access to, and support for, their STAR-CD CFD code. 

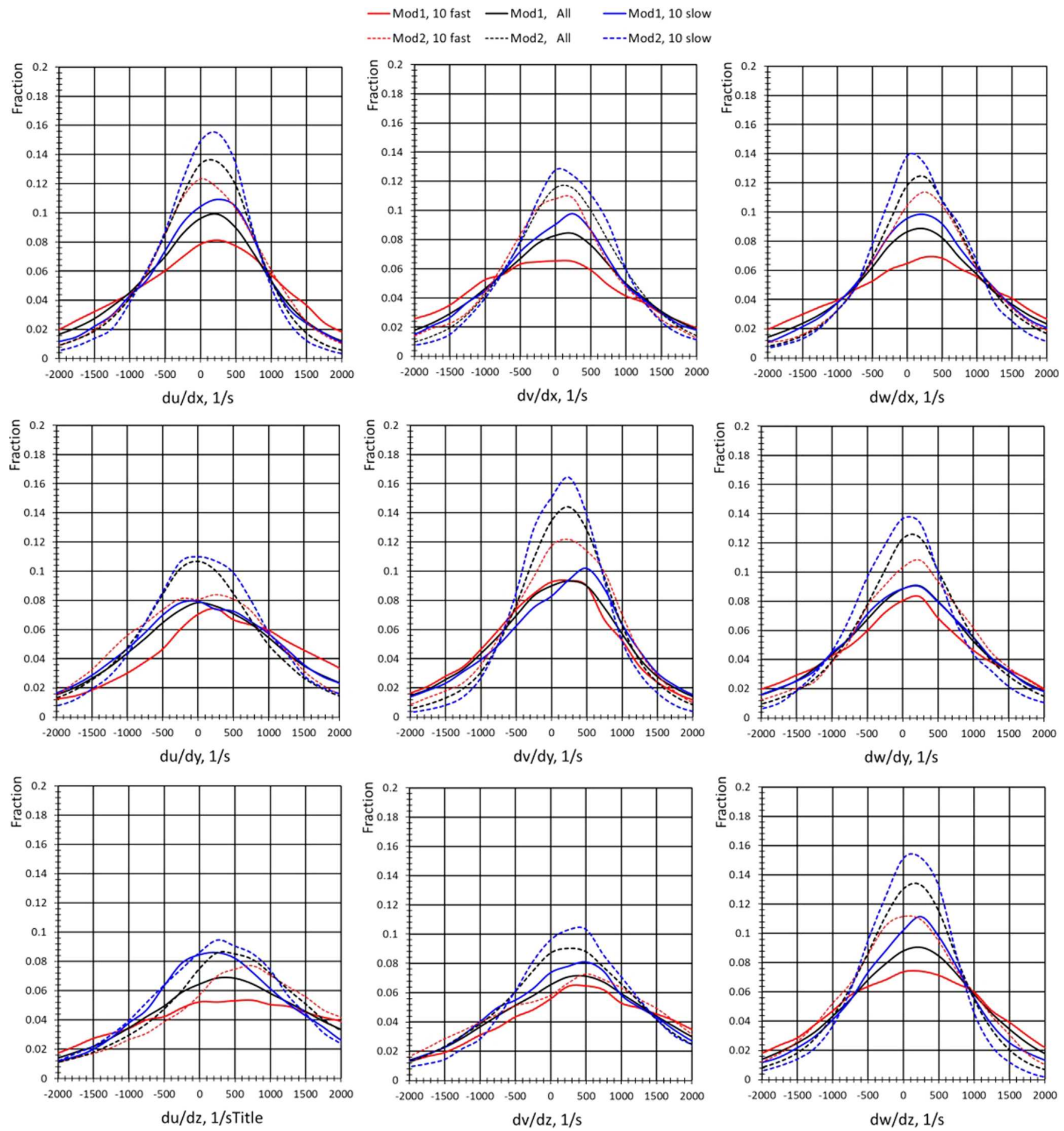

Figure 14

Distributions of nine components of the velocity gradient tensor in the volume centered at the spark plug at SOIgn ( $342^{\circ}$ aTDCe) for two different LES models. The distributions are sampled at all volume nodes in the region for the 60 simulated cycles (total sample size of $370 \mathrm{k}$ ). Three distributions are shown for each component: all 60 cycles, the 10 fastest-burning cycles, and the 10 slowest-burning cycles. 

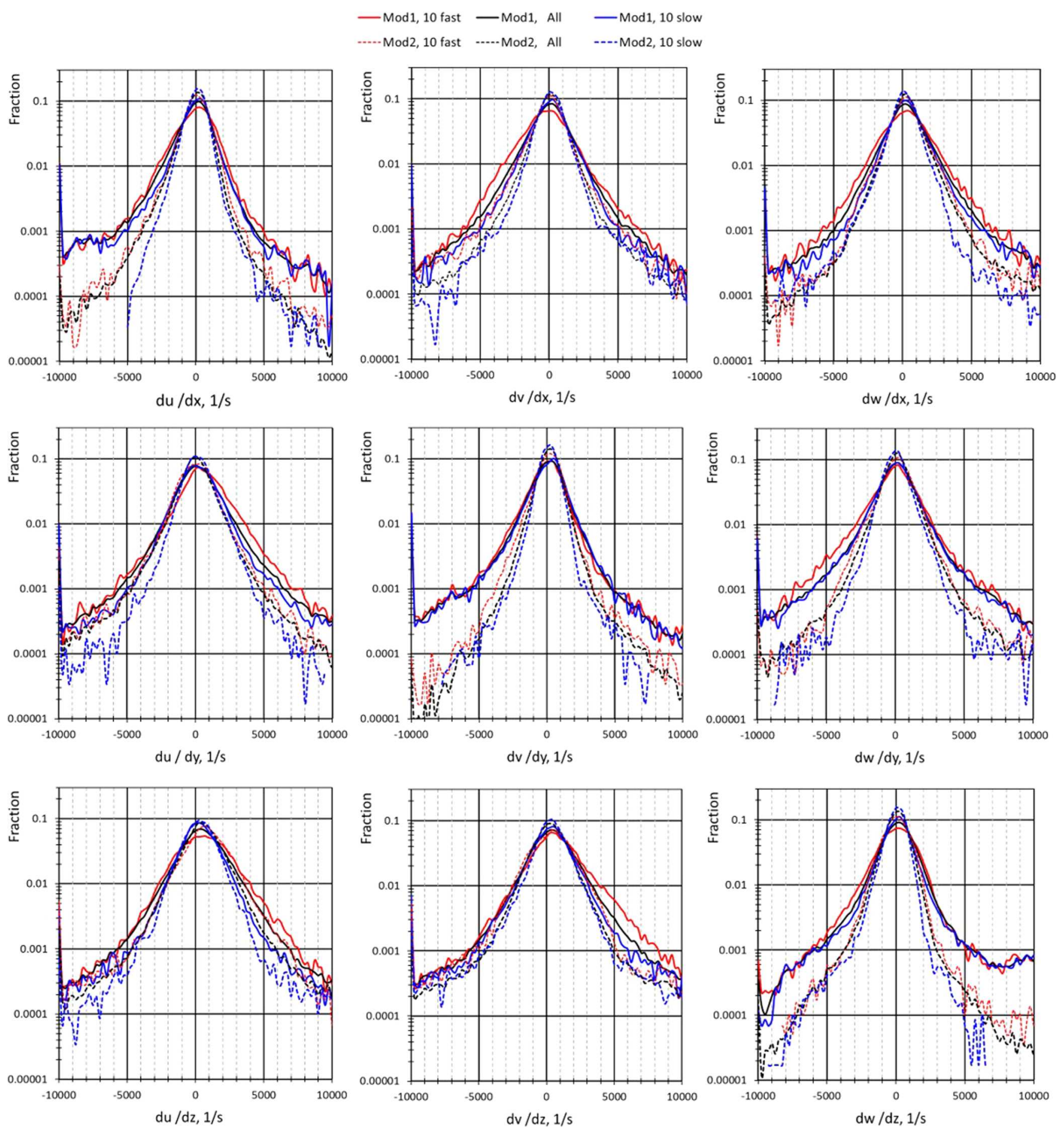

Figure 15

Distributions of nine components of the velocity gradient tensor in the volume centered at the spark plug at SOIgn $\left(342^{\circ}\right.$ aTDCe) for two different LES models. The distributions are sampled at all volume nodes in the region for the 60 simulated cycles (total sample size of $370 \mathrm{k}$ ). Three distributions are shown for each component: all 60 cycles, the 10 fastest-burning cycles, and the 10 slowest-burning cycles. This is the same as Figure 14, but plotted using a logarithmic scale. 


\section{REFERENCES}

1 Ozdor N., Dulger M., Sher E. (1994) Cyclic variability in spark ignition engines: a literature survey, SAE Technical Paper 940987.

2 Johansson B. (1996) Cycle to cycle variations in S.I. engines the effects of fluid flow and gas composition in the vicinity of the spark plug on early combustion, SAE Technical Paper 962084.

3 Pajot O. (2000) Étude expérimentale de l'influence de l'aérodynamique sur le comportement et la structure du front de flamme dans les conditions d'un moteur à allumage commandé, Thèse, University of Orléans, Orléans, France.

4 Ayala F.A., Heywood J.B. (2007) Lean SI engines: the role of combustion variability in defining lean limits, SAE Technical Paper 2007-24-0030.

5 Lacour C., Pera C. (2011) An experimental database dedicated to the study and modelling of cyclic variability in spark-ignition engines with LES, SAE Technical Paper 2011-01-1282.

6 Baum E., Peterson B., Böhm B., Dreizler A. (2014) On the validation of LES applied to internal combustion engine flows, Part 1: comprehensive experimental database, Flow Turb. Combust. 92, 1-2, 269-297.

7 Schiffmann P. (2016) Root causes of cycle-to-cycle combustion variations in spark ignited engines, $P h D$ thesis, University of Michigan, Ann Arbor, MI, USA.

8 Truffin K., Angelberger C., Richard S., Pera C. (2015) Using large-eddy simulation and multivariate analysis to understand the sources of combustion cyclic variability in a spark-ignition engine, Combust. Flame 162, 12, 4371-4390.

9 Bates S.C. (1989) Flame imaging studies of cycle-by-cycle combustion variation in a SI four-stroke engine, SAE Technical Paper 892086.

10 Pera C., Knop V., Reveillon J. (2015) Influence of flow and ignition fluctuations on cycle-to-cycle variations in early flame kernel growth, Proc. Combust. Inst. 35, 2897-2905.

11 Granet V., Vermorel O., Lacour C., Enaux B., Dugué V., Poinsot T. (2012) Large-eddy simulation and experimental study of cycle-to-cycle variations of stable and unstable operating points in a spark ignition engine, Combust. Flame 159, 1562-1575.

12 Goryntsev D., Sadiki A., Klein M., Janicka J. (2009) Large eddy simulation based analysis of the effects of cycle-to-cycle variations on air-fuel mixing in realistic DISI IC-engines, Proc. Combust. Inst. 32, 2759-2766.

13 Goryntsev D., Sadiki A., Janicka J. (2013) Analysis of misfire processes in realistic direct injection spark ignition engine using multi-cycle large eddy simulation, Proc. Combust. Inst. 34, 2969-2976.

14 Heywood J.B. (1988) Internal combustion engine fundamentals, McGraw Hill, New York.

15 Matekunas F.A. (1983) Modes and measures of cyclic combustion variability, SAE Technical Paper 830337.

16 Beretta G.P., Rashidi M., Keck J.C. (1983) Turbulent flame propagation and combustion in spark ignition engines, Combust. Flame 51, 217-245.

17 Abraham J., Bracco F.V., Reitz R.D. (1985) Comparisons of computed and measured premixed charge engine combustion, Combust. Flame 60, 309-322.
18 Arpaci V.S., Ko Y., Lim M.T., Lee H.S. (2003) Spark kernel development in constant volume combustion, Combust. Flame 135, 315-322.

19 Liu K., Haworth D.C., Yang X.S., Gopalakrishnan V. (2013) Large-eddy simulation of motored flow in a two-valve piston engine: POD analysis and cycle-to-cycle variations, Flow Turb. Combust. 91, 373-403.

20 Schiffmann P., Gupta S., Reuss D., Sick V., Yang X., Kuo T.-W. (2016) TCC-III engine benchmark for large-eddy simulation of IC engine flows, Oil Gas Sci. Technol. - Rev. IFP 71, 1, 1-27.

21 Sick V., Reuss, D.L., Yang X., Kuo T.-W. (2014) https:// deepblue.lib.umich.edu/handle/2027.42/108382.

22 Reuss D.L. (2000) Cyclic variability of large-scale turbulent structures in directed and undirected IC engine flows, SAE Technical Paper 2000-01-0246.

23 AbrahamP.S., Yang X., Gupta S., Kuo T.-W., Reuss D.L., Sick V. (2016) Flow-pattern switching in a motored spark ignition engine, SAE Int. J. Eng. Res. 16, 323-339.

24 Montorfano A., Piscaglia F., Onorati A. (2015) An extension of the dynamic mesh handling with topological changes for LES of ICE in OpenFOAM, SAE Technical Paper 2015-01-0384.

25 Ameen M.M., Yang X., Kuo T.-W., Xue Q., Som S. (2015) LES for simulating the gas exchange process in a spark ignition engine, in: ICEF2015-1002, Proceedings of the ASME 2015 Internal Combustion Engine Division Fall Technical Conference, Houston, TX, 8-11 November, 2015.

26 Zhao H., Ladommatos N. (2001) Engine Combustion Instrumentation and Diagnostics, SAE International, Warrendale, PA, p. 842.

27 Siemens PLM Software (2016) http://mdx.plm.automation. siemens.com/star-cd.

28 Colin O., Ducros F., Veynante D., Poinsot T. (2000) A thickened flame model for large eddy simulations of turbulent premixed combustion, Phys. Fluids 12, 1843-1863.

29 Charlette F., Meneveau C., Veynante D. (2002) A power-law flame wrinkling model for LES of premixed turbulent combustion. Part I: non-dynamic formulation and initial tests, Combust. Flame 131, 159-180.

30 Colin O., Truffin K. (2011) A spark ignition model for large eddy simulation based on an FSD transport equation (ISSIMLES), Proc. Combust. Inst. 33, 3097-3104.

31 Shekhawat Y. (2017) Large-eddy simulations of motored flow and combustion in a homogeneous-charge spark-ignition engine, Ph.D. thesis, The Pennsylvania State University, University Park, PA, USA.

32 d'Adamo A., Breda S., Fontanesi S., Cantore G. (2015) LES modelling of spark-ignition cycle-to-cycle variability on a highly downsized DISI engine, SAE Int. J. Eng. 8, 2029-2041.

33 Duclos J.M., Colin O. (2001) Arc and kernel tracking ignition model for 3D spark-ignition engine calculations, COMODIA, 343-350.

34 Verhoeven D. (1995) Spark heat transfer measurements in flowing gases, SAE Technical Paper 952450.

35 Petersen B.R., Ghandhi J.B. (2010) High resolution scalar dissipation and turbulence length scale measurements in an internal combustion engine, SAE Technical Paper 2010-01-0185.

Manuscript submitted in 15 November 2016 Manuscript accepted in 7 August 2017 Published online in October 2017 